\title{
Suppression of DNA Double-Strand Break Formation by DNA Polymerase $\beta$ in Active DNA Demethylation Is Required for Development of Hippocampal Pyramidal Neurons
}

\author{
Akiko Uyeda, ${ }^{1}$ Kohei Onishi, ${ }^{1}$ Teruyoshi Hirayama, ${ }^{1,2,3}{ }^{\circledR}$ Satoko Hattori, ${ }^{4}{ }^{\circledR}$ Tsuyoshi Miyakawa, ${ }^{4}$ \\ ${ }^{\circ}$ Takeshi Yagi, ${ }^{1,2}{ }^{\circledR}$ Nobuhiko Yamamoto, ${ }^{1}$ and ${ }^{\circledR}$ Noriyuki Sugo ${ }^{1}$ \\ ${ }^{1}$ Graduate School of Frontier Biosciences, Osaka University, Suita, Osaka 565-0871, Japan, ${ }^{2}$ AMED-CREST, Japan Agency for Medical Research and \\ Development, Suita, Osaka 565-0871, Japan, ${ }^{3}$ Department of Anatomy and Developmental Neurobiology, Tokushima University Graduate School of Medical \\ Sciences, Kuramoto, Tokushima 770-8503, Japan, and ${ }^{4}$ Institute for Comprehensive Medical Science, Fujita Health University, Toyoake, Aichi 470-1192, Japan
}

Genome stability is essential for brain development and function, as de novo mutations during neuronal development cause psychiatric disorders. However, the contribution of DNA repair to genome stability in neurons remains elusive. Here, we demonstrate that the base excision repair protein DNA polymerase $\beta(\mathrm{Pol} \beta)$ is involved in hippocampal pyramidal neuron differentiation via a TET-mediated active DNA demethylation during early postnatal stages using Nex-Cre/Pol ${ }^{\text {flfl }}$ mice of either sex, in which forebrain postmitotic excitatory neurons lack Pol $\beta$ expression. Pol $\beta$ deficiency induced extensive DNA double-strand breaks (DSBs) in hippocampal pyramidal neurons, but not dentate gyrus granule cells, and to a lesser extent in neocortical neurons, during a period in which decreased levels of 5-methylcytosine and 5-hydroxymethylcytosine were observed in genomic DNA. Inhibition of the hydroxylation of 5-methylcytosine by expression of microRNAs miR-29a/b-1 diminished DSB formation. Conversely, its induction by TET1 catalytic domain overexpression increased DSBs in neocortical neurons. Furthermore, the damaged hippocampal neurons exhibited aberrant neuronal gene expression profiles and dendrite formation, but not apoptosis. Comprehensive behavioral analyses revealed impaired spatial reference memory and contextual fear memory in adulthood. Thus, Pol $\beta$ maintains genome stability in the active DNA demethylation that occurs during early postnatal neuronal development, thereby contributing to differentiation and subsequent learning and memory.

Key words: DNA demethylation; DNA double-strand break; DNA repair; hippocampal development; learning and memory; neuronal differentiation

\section{Significance Statement}

Increasing evidence suggests that de novo mutations during neuronal development cause psychiatric disorders. However, strikingly little is known about how DNA repair is involved in neuronal differentiation. We found that $\operatorname{Pol} \beta$, a component of base excision repair, is required for differentiation of hippocampal pyramidal neurons in mice. $\operatorname{Pol} \beta$ deficiency transiently led to increased DNA double-strand breaks, but not apoptosis, in early postnatal hippocampal pyramidal neurons. This aberrant double-strand break formation was attributed to active DNA demethylation as an epigenetic regulation. Furthermore, the damaged neurons exhibited aberrant gene expression profiles and dendrite formation, resulting in impaired learning and memory in adulthood. Thus, these findings provide new insight into the contribution of DNA repair to the neuronal genome in early brain development.

Received Feb. 3, 2020; revised 0ct. 2, 2020; accepted 0ct. 16, 2020.

Author contributions: A.U., S.H., T.M., T.Y., N.Y., and N.S. designed research; A.U., K.O., T.H., S.H., and N.S. performed research; A.U., K.O., T.H., S.H., T.M., T.Y., N.Y., and N.S. analyzed data; A.U. and N.S. wrote the first draft of the paper; A.U., K.O., T.H., S.H., T.M., T.Y., N.Y., and N.S. edited the paper; A.U., N.Y., and N.S. wrote the paper.

This work was supported by Ministry of Education, Culture, Sports, Science and Technology KAKENHI on Dynamic regulation of brain function by Scrap \& Build system (№. 16H06460) to N.Y., Japan Society for the Promotion of Science KAKENHI Grants 15K14350 and 17K07109 to N.S., 16H06276 (AdAMS) to N.S. and T.M., and Japan Agency for Medical Research and Development-Core Research for Evolutional Science and Technology to T.Y. We thank Dr. K.A. Nave for the Nex-Cre mice; Dr. K. Rajewsky for Pol $\beta$ flox mice; and Dr. I. Smith for critical reading of the manuscript.

The authors declare no competing financial interests.

Correspondence should be addressed to Noriyuki Sugo at sugo@fbs.osaka-u.ac.jp.

https://doi.org/10.1523/JNEUROSCI.0319-20.2020

Copyright $\odot 2020$ the authors

\section{Introduction}

Genome stability is crucial for both genetic and epigenetic regulation underlying gene expression in the brain throughout life. DNA repair is essential to maintain genome stability and has been well characterized through studies on cancer and immune cell differentiation in mammals (Lindahl and Wood, 1999; Alt et al., 2013). In the nervous system, mouse models reveal that DNA repair dysfunction in neural progenitors frequently leads to genome instability and neuronal apoptosis during the period of neurogenesis (McKinnon, 2013). Genetic diseases related to DNA repair also include microcephaly, developmental disorders, and psychiatric disorders (McKinnon, 2013; Madabhushi et al., 
2014). In addition, accumulation of somatic mutations in neurons during development has been implicated in developmental brain disorders, such as autism and schizophrenia (Poduri et al., 2013; McConnell et al., 2017). These studies suggest that DNA repair is likely to be critical for normal brain development and function. However, while DNA repair has been characterized in mitotic cells, including neural progenitors, its role in neurons as postmitotic cells remains unclear. Thus, it is important to uncover novel aspects of DNA repair in neuronal differentiation and function.

Base excision repair (BER) is mainly involved in the removal of DNA base damage and apurinic/apyrimidinic sites (Wilson et al., 2000). In addition, recent studies have revealed that BER also plays a role in the active DNA demethylation process as an epigenetic regulation (Wu and Zhang, 2017). In this process, 5-methylcytosine $(5 \mathrm{mC})$ is initially oxidized by TET enzymes and is converted to 5-hydroxymethylcytosine $(5 \mathrm{hmC})$; the modified base is finally recognized by thymine DNA glycosylase and replaced with cytosine by DNA polymerase $\beta(\operatorname{Pol} \beta)$ and the Xrcc1/Lig3 complex (Weber et al., 2016). DNA methylation and demethylation often play a central role in cell differentiation (Wu and Zhang, 2017). In the neuronal epigenome, dynamic changes in the DNA methylation level are observed during brain development (Lister et al., 2013; Simmons et al., 2013; Sharma et al., 2016) and affect neuronal gene expression, which is implicated in neurogenesis, maturation, and plasticity (Moretti et al., 2006; Feng et al., 2010; Sanosaka et al., 2017). This regulation also contributes to learning and memory (Kaas et al., 2013; Rudenko et al., 2013; Li et al., 2014; Gontier et al., 2018).

Studies using conventional Pol $\beta$-deficient mice show increased neuronal apoptosis during the period of neurogenesis in the developing nervous system rather than in other tissues, and the mice die just after birth (Sugo et al., 2000). The p53-dependent pathway regulates neuronal apoptosis after the final mitosis (Sugo et al., 2004). Our previous study focusing on spatiotemporal roles using forebrain-specific conditional $\mathrm{KO}$ Emxl-Cre/Pol $\beta^{\text {fl/fl }}$ and Nex-Cre/Pol $\beta^{\text {flfl }}$ mice indicates that $\operatorname{Pol} \beta$ deficiency in neural progenitors rather than in postmitotic neurons specifically leads to an increase of DNA double-strand breaks (DSBs) in the embryonic neocortex (NCX) (Onishi et al., 2017). The accumulation of DSBs frequently induces neuronal apoptosis and abnormal axon projection. Furthermore, impairment of the DNA demethylation process is a potential cause of DSBs in $\mathrm{Pol} \beta$-deficient progenitors, suggesting that epigenetic regulation via $\mathrm{BER}$, including $\operatorname{Pol} \beta$ in neural progenitors, is essential for neuronal survival and differentiation. However, how $\operatorname{Pol} \beta$ contributes to subsequent neuronal development, gene expression, and further cognitive function is not fully understood.

To address this issue, we investigated the role of $\operatorname{Pol} \beta$ using Nex-Cre/Pol $\beta^{f l f l}$ mice, in which postmitotic excitatory neurons lack $\operatorname{Pol} \beta$ expression. The mutant mice exhibited extensive DSB formation, but not apoptosis, in hippocampal pyramidal neurons more so than in neocortical neurons during early postnatal stages, in which the levels of $5 \mathrm{mC}$ and $5 \mathrm{hmC}$ in the genome decreased. In vivo manipulation of active DNA demethylation altered the extent of DSBs in $\operatorname{Pol} \beta$-deficient neurons. Furthermore, $\operatorname{Pol} \beta$ deficiency affected gene expression profiles and dendritic morphology of developing hippocampal pyramidal neurons, and impaired hippocampus-related learning and memory. These findings suggest that genome stability mediated by $\operatorname{Pol} \beta$ is required for active DNA demethylation leading to normal postnatal neuronal development and memory function.

\section{Materials and Methods}

Animals. All experiments were conducted under the guidelines for laboratory animals of the Graduate School of Frontier Biosciences, Osaka University. The protocol was approved by the Animal Care and Use Committee of the Graduate School of Frontier Biosciences, Osaka University and Fujita Health University. Nex ${ }^{\mathrm{Cre} /+} \mathrm{Pol}^{\mathrm{fl} / \mathrm{fl}}$ (Nex-Cre/ Pol $\beta^{f l / f l}$ ) mice were generated as described previously (Onishi et al., 2017). Both male and female mice were used in all experiments, except RNA-seq analysis and the behavioral test. Noon of the day on which the vaginal plug was detected was designated as embryonic day 0.5 (E0.5) and the day of birth was designated as postnatal day 0 (P0). Genotyping was performed using the following primers: $\operatorname{Pol} \beta$ locus: $5^{\prime}$-CCAC ACCGAAGTCCTCTGAT-3' ${ }^{\prime}$ ' $^{\prime}$-AGGCTGGCCTCAGACTCATA- ${ }^{\prime}$ ' and 5'-CTGGCTCACGTTCTTCTC-3'; Cre locus: 5'-GCAGAACCTGAAG ATGTTCGCGAT-3' and 5' -AGGTATCTCTGACCAGAGTCATCC- ${ }^{\prime}$.

Cell cultures. Pregnant mice were deeply anesthetized with pentobarbital $(50 \mathrm{mg} / \mathrm{kg}$, i.p.). Neocortices were dissected from E16.5 embryos in ice-cold HBSS and then minced with fine scissors in PBS, pH 7.4. The minced tissues were incubated with $0.125 \%$ trypsin and $0.02 \%$ EDTA in PBS for $5 \mathrm{~min}$ at $37^{\circ} \mathrm{C}$, and then triturated thoroughly using a fire-polished Pasteur pipette. After centrifugation, the cells were resuspended in DMEM/F12 medium (Thermo Fisher Scientific) supplemented with B27 (Thermo Fisher Scientific) and 5\% FBS (Hyclone). A suspension containing $2.0 \times 10^{5}$ cells was plated with culture medium on a $12 \mathrm{~mm}$ micro cover glass (Matsunami) in a multiwell dish (Thermo Fisher Scientific) coated with $0.1 \mathrm{mg} / \mathrm{ml}$ poly-L-ornithine (P3655, Sigma Millipore). The cultures were maintained at $37^{\circ} \mathrm{C}$ in an environment of $5 \% \mathrm{CO}_{2}$ and humidified $95 \%$ air.

Plasmids. pFN21AE2295, containing HaloTag-human TET1 cDNA, was purchased from Promega. To generate TET1 catalytic domain (TET1CD) expression vector pCAGGS-TET1CD, TET1CD was amplified from pFN21AE2295 by PCR with the following primers: TET1CD forward, $5^{\prime}$-ATGGAACTGCCCACCTGCAGCTGTCT- $3^{\prime}$ and TET1CD reverse, 5'-TCAGACCCAATGGTTATAGGGCCCCG-3'. The PCR product was subcloned into pGEM-T Easy vector (A1360, Promega). An EcoRI-digested fragment containing TET1CD was then ligated to EcoRI-digested pCAGGS vector. To generate pCAGGS-miR-29a/b-1, the miR-29a/b-1 cluster locus was amplified from mouse genomic DNA by PCR with the following primers: miR-29a/b-1 forward, 5' -TGTGTTGCTTTGCCTTTGAGAGGA-3', and miR-29a/b-1 reverse, $5^{\prime}$-CACATAGGGATAGTCACCTAGCCTG-3'; the product was subcloned into pGEM-T Easy vector. An EcoRI-digested fragment containing miR-29a/b-1 locus was then ligated to EcoRI-digested pCAGGS vector. Supernova vectors pTRE-Flpe-WPRE (pK036) and pCAG-FRT-stop-FRT-tRFP-ires-tTA-WPRE (pK037) were kindly gifted from T. Iwasato (Luo et al., 2016). These vectors were cotransfected with pCAGGS-EGFP. All plasmids were purified with the PureLink HiPure Plasmid Maxiprep Kit (Invitrogen), and then dissolved in PBS.

In utero electroporation. In utero electroporation was performed on E15.5 pregnant mice as previously described (Tomita et al., 2011). Pregnant mice were deeply anesthetized with isoflurane (Wako Chemicals) using inhalation anesthesia equipment (KN-1071-1, Natsume). Plasmids (1-3 $\mu \mathrm{g})$ were injected to the lateral ventricle with a glass micropipette connected to an injector (IM-30, Narishige). Electric pulses were delivered with disk-type electrodes (LF650P3 or LF650P5, BEX) connected to an electroporator (CUY21, BEX). Five $35 \mathrm{~V}$ pulses of $50 \mathrm{~ms}$ duration were applied at intervals of $950 \mathrm{~ms}$.

Pharmacological treatment. For a cell survival assay, cells at 3-4 DIV were incubated with culture medium containing 0-0.8 mM methylmethanesulfonate (MMS, 129925, Sigma Millipore) or 0-8 $\mu \mathrm{M}$ etoposide (E1383, Sigma Millipore) for $1 \mathrm{~h}$, washed once with DMEM/F12 medium, and allowed to recover in conditioned medium for $24 \mathrm{~h}$. To induce DNA base damage, cells at 14 DIV were treated with culture medium containing $0.4 \mathrm{~mm}$ MMS for $1 \mathrm{~h}$, and then fixed. To induce Tet-dependent DNA demethylation, cells at 14 DIV were treated with culture medium containing $100 \mu \mathrm{g} / \mathrm{ml} \mathrm{L}$-ascorbic acid 2-phosphate (vitamin C, 49752, Sigma Millipore) for $24 \mathrm{~h}$, and then fixed.

Immunostaining. Mice were deeply anesthetized and perfused with $2 \%$ PFA in $0.1 \mathrm{M} \mathrm{PB}, \mathrm{pH}$ 7.4. Their brains were postfixed in the same fixative on ice for $2 \mathrm{~h}$, equilibrated with $25 \%$ sucrose in PBS, frozen in OCT 
compound (Sakura Finetech), and then sectioned at 10 or $20 \mu \mathrm{m}$ using a cryostat (CM1850, Leica Microsystems). The sections were permeabilized and blocked for $1 \mathrm{~h}$ at room temperature in buffer $\mathrm{G}(0.1 \%$ or $1.0 \%$ Triton X-100, 5\% normal goat serum [Vector Laboratories] in PBS). They were then incubated at $4^{\circ} \mathrm{C}$ overnight with the following primary antibodies diluted in buffer G: rabbit polyclonal anti-Tbr1 (ab31940, Abcam) at 1:500, rat monoclonal anti-Ctip2 (ab18465, Abcam) at 1:800, rabbit polyclonal anti-CDP (Cux1) (sc-13024, Santa Cruz Biotechnology) at 1:200, rabbit polyclonal anti-Prox1 (AB5475, Merck) at 1:1000, rabbit polyclonal anti-cleaved caspase-3 (Asp175) (\#9661, Cell Signaling) at 1:250, rabbit polyclonal anti-histone H2AX phospho Ser139 (39117, Active Motif) at 1:200, rabbit polyclonal anti-53BP1 (GTX102595, Gene Tex) at 1:200, rat monoclonal anti-53BP1 (933001, BioLegend) at 1:200, rabbit monoclonal anti-XRCC1 (ab134056, Abcam) at 1:200, rat monoclonal anti-GFP (GF090R, Nacalai Tesque) at 1:1000, rabbit anti-5mC (\#28692, Cell Signaling Technology) at 1:1000, and rabbit polyclonal anti-5hmC (39769, Active Motif) at 1:20,000. Immunostaining of $\operatorname{Pol} \beta$ was performed as described previously (Onishi et al., 2017). For XRCC1 and 5hmC immunostaining, the sections were treated with $10 \mathrm{~mm}$ sodium citrate buffer, $\mathrm{pH} 6.0$, for $10 \mathrm{~min}$ at $98^{\circ} \mathrm{C}$ using an autoclave. For coimmunostaining with anti-5hmC and -GFP antibodies, anti-GFP antibody was preincubated overnight at $4^{\circ} \mathrm{C}$ before the antigen retrieval step. For $5 \mathrm{mC}$ immunostaining, sections were treated with $0.1 \%$ Triton X-100 in PBS for $3 \mathrm{~h}$ before autoclaving. Primary antibodies were detected by incubation with the secondary antibodies Alexa-488-conjugated anti-rabbit IgG (A-11034, Invitrogen), Alexa-488-conjugated anti-rat IgG (A-11006, Invitrogen), Alexa-594-conjugated anti-rabbit IgG (A21207, Invitrogen), Cy3-conjugated anti-mouse IgG (AP192C, Millipore), Cy3-conjugated anti-rabbit IgG (AP182C, Millipore), and Cy3-conjugated anti-rat IgG (AP136C, Millipore), in all cases diluted at 1:400 in buffer $\mathrm{G}$ for $2 \mathrm{~h}$ at room temperature. Finally, the sections were mounted with a medium containing 0.1\% DAPI (Sigma Millipore), 1, 4-diazabicyclo [2, 2, 2] octane (Sigma Millipore), and $50 \%$ or $80 \%$ glycerol in $50 \mathrm{~mm}$ Tris$\mathrm{HCl}, \mathrm{pH} 8.0$.

For morphologic analysis of dendrites, mice were perfused with $4 \%$ PFA in $0.1 \mathrm{M} \mathrm{PB}, \mathrm{pH}$ 7.4. The brains were postfixed in the same fixative for $24 \mathrm{~h}$ at $4^{\circ} \mathrm{C}$, and equilibrated with $25 \%$ sucrose-PBS overnight at $4^{\circ} \mathrm{C}$. The brains were cut into $200 \mu \mathrm{m}$ coronal sections using a vibratome (DTK-1000, D.S.K.). The free-floating sections were permeabilized and blocked in buffer $\mathrm{G}$ for $1 \mathrm{~h}$ at room temperature. They were then incubated with primary antibodies, rat monoclonal anti-GFP (GF090R, Nacalai Tesque) at 1:2000 and rabbit polyclonal anti-tRFP (AB233, Evrogen) at 1:2000, in buffer $\mathrm{G}$ overnight at $4^{\circ} \mathrm{C}$. The sections were washed 3 times with $0.1 \%$ Triton X-100 in PBS for $1 \mathrm{~h}$, and incubated with secondary antibodies in buffer $\mathrm{G}$ overnight at $4^{\circ} \mathrm{C}$. The sections were then washed 3 times with $0.1 \%$ Triton X-100 in PBS for $1 \mathrm{~h}$ and mounted with DAPI-containing mounting medium.

Cultured cells were fixed with 4\% PFA in PBS for $10 \mathrm{~min}$ at room temperature, washed 3 times with PBS for $10 \mathrm{~min}$, permeabilized, and blocked in buffer $\mathrm{G}$. The cells were then incubated overnight at $4^{\circ} \mathrm{C}$ in buffer $\mathrm{G}$ with the following antibodies: mouse monoclonal anti-Tuj1 (MAB1195, R\&D Systems) at 1:1000, rabbit polyclonal anti-histone $\mathrm{H} 2 \mathrm{AX}$ phospho Ser139 at 1:200, and rabbit polyclonal anti $5 \mathrm{hmC}$ at 1:20,000. For $5 \mathrm{hmC}$ immunostaining, the cells were incubated with $1 \mathrm{M}$ $\mathrm{HCl}$ for $30 \mathrm{~min}$ at $37^{\circ} \mathrm{C}$ and washed 3 times with PBS for $30 \mathrm{~min}$ before permeabilization. Primary antibodies were detected by incubation for $2 \mathrm{~h}$ at room temperature in buffer $\mathrm{G}$ with the following secondary antibodies: Alexa-488-conjugated anti rabbit IgG at 1:400 and Cy3-conjugated anti-mouse IgG at 1:400. The cells were mounted with DAPIcontaining mounting medium.

ISH. cDNA fragment encoding mouse Gad1 (NM_008077.5, nucleotides 311-929) subcloned into pBluescript II SK(+) vector was kindly gifted from T. Kitsukawa. The preparation of RNA probe and ISH were performed as described previously (Zhong et al., 2004).

Image analysis. Fluorescence images were obtained by confocal microscopy (Nikon Eclipse FN with EZ-C1, Nikon; Nikon Eclipse Ti2 with Andor Dragonfly 200, Oxford Instruments) with $10 \times / 0.3,20 \times / 0.75$, $40 \times / 0.95$, and $60 \times / 1.4$ objective lenses (Nikon). All images were imported into ImageJ to adjust brightness and contrast. To acquire images of $\gamma \mathrm{H} 2 \mathrm{AX}$ and XRCC1 in DAPI-stained nuclei, confocal $z$-stack images were collected at $0.5 \mu \mathrm{m}$ intervals with a $40 \times$ objective lens. For focus counting, noise in the images was removed by Gaussian filter and subtraction from the background, and foci were detected with the "Find Maxima" tool in ImageJ. To obtain images of RFP-labeled apical and basal dendrites in dorsal hippocampal CA1 regions, confocal $z$-stack images were collected at $1 \mu \mathrm{m}$ intervals through the $200 \mu \mathrm{m}$ sections using a $20 \times$ objective lens. To obtain images of RFP-labeled spines, confocal $z$-stack images were collected at $0.18 \mu \mathrm{m}$ intervals through the 200 $\mu \mathrm{m}$ sections using a $60 \times$ objective lens. Quantitative analysis of dendrite morphology was performed using the ImageJ plug-ins Simple Neurite Tracer (Longair et al., 2011) and L-measure (Scorcioni et al., 2008).

Immunoblot analysis. Genomic DNA was extracted using a DNeasy Blood \& Tissue kit (QIAGEN). The DNA was eluted with TE buffer and stored at $-30^{\circ} \mathrm{C}$ until required. The genomic DNA was denatured in 20 $\mathrm{mm}$ Tris- $\mathrm{HCl}, \mathrm{pH} 8.0$, for $10 \mathrm{~min}$ at $98^{\circ} \mathrm{C}$ and chilled on ice. Serially diluted DNA samples $(1000,500,250,125 \mathrm{ng} / 200 \mu \mathrm{l})$ were blotted onto a positively charged nylon membrane (INYC00010, Millipore) using a slot blot apparatus (Bio-Dot, Bio-Rad). The membrane was air-dried, and UV-crosslinked using an ultraviolet crosslinker (CL-1000, UVP). The membrane was stained with $0.02 \%$ methylene blue (Nacalai Tesque) for $30 \mathrm{~min}$ at room temperature as a loading control. The membrane was then washed with TBS containing 0.1\% Tween-20 (TBS-T) and blocked in 5\% nonfat dry milk (\#9999, Cell Signaling Technology) diluted with TBS-T for $1 \mathrm{~h}$ at room temperature. The membrane was incubated with the following primary antibodies diluted in 5\% nonfat dry milk/TBS-T overnight at $4^{\circ} \mathrm{C}$ : rabbit polyclonal anti-5hmC antibody at 1:5000 and mouse monoclonal anti-5mC antibody (39649, Active Motif) at 1:2000. Primary antibodies were detected by incubation with the following secondary antibodies diluted in 5\% skim milk in TBS-T for $2 \mathrm{~h}$ at room temperature: peroxidase-conjugated anti-rabbit IgG antibody (711-035-152, Jackson ImmunoResearch Laboratories) at 1:5000 and peroxidase-conjugated anti-mouse IgG (01803-44, Nacalai Tesque) at 1:5000. The signal was visualized by chemiluminescence (ECL Select, GE Healthcare) and imaged by LAS-3000UV mini (Fujifilm).

RNA-seq analysis. Total RNA was extracted from hippocampus of P15 Pol $\beta^{f l / f l}$ and Nex-Cre/Pol $\beta^{f l / f l}$ male mice using a RNeasy Plus Mini Kit (QIAGEN) following the manufacturer's procedure. Library preparation was performed using a TruSeq stranded mRNA sample prep kit (Illumina) according to the manufacturer's instructions. Whole-transcriptome sequencing was applied to the RNA samples with an Illumina HiSeq 2500 platform in a 75 base single-end mode. Illumina Casava version1.8.2 software was used for base calling. Sequenced reads were mapped to the mouse reference genome sequences (mm10) using TopHat version 2.0.13 in combination with Bowtie2 version 2.2.3 and SAMtools version 0.1.19. The number of fragments per kilobase of exon per million mapped fragments (FPKMs) was calculated using Cufflinks version 2.2.1. Differentially expressed genes (DEGs) were defined by fold change $>1.2(p<0.05, n=3)$. Functional annotation and pathway analysis were performed with Ingenuity pathway analysis (QIAGEN). Correlation analysis of expression profiles was performed with the Illumina correlation engine software (Illumina). Raw RNA-Seq data are available on DDBJ GEA (accession GEA: E-GEAD-386).

Behavioral test. Behavioral tests were conducted at the Institute for Comprehensive Medical Science, Fujita Health University (Joint Usage/ Research Center for Genes, Brain and Behavior accredited by Ministry of Education, Culture, Sports, Science and Technology). The comprehensive behavioral test was performed as described previously (Shoji et al., 2018) with male adult (>3 months) Nex-Cre/Pol $\beta^{f l f l}$ mice and their littermate controls. In brief, the Barnes maze test was performed with a white circular surface, $1.0 \mathrm{~m}$ in diameter, with 12 holes equally spaced around the perimeter and elevated $75 \mathrm{~cm}$ from the floor. A black Plexiglas escape box was located under one of the holes and represented the target. The location of the target was consistent for each mouse but randomized between mice. The visual cues were in the four corners of the experimental room. One or two trials per day were performed. The number of errors, latency to reach the target, and distance traveled before mice first reached their target were automatically calculated by image analysis. One day or 1 month after the last training session, a 
A
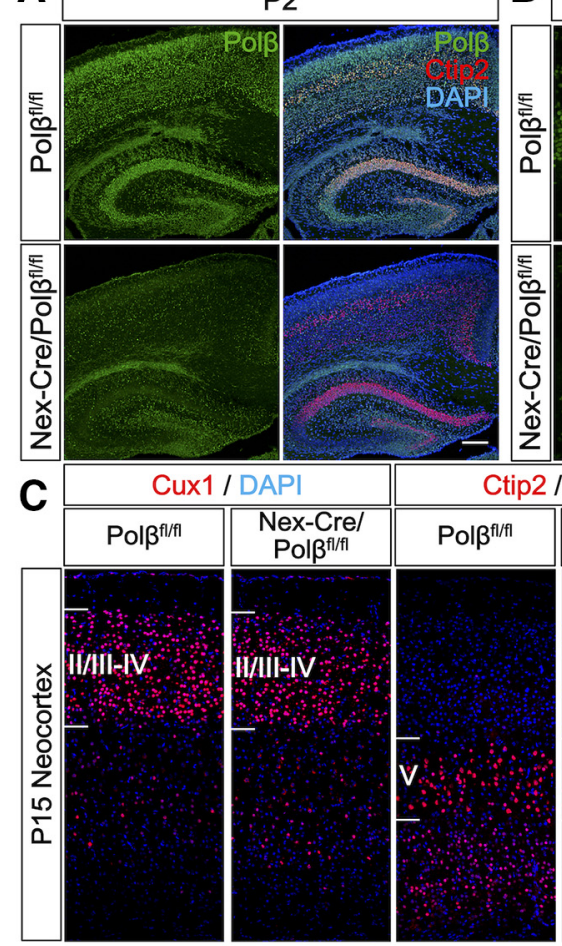

$\mathbf{F}$

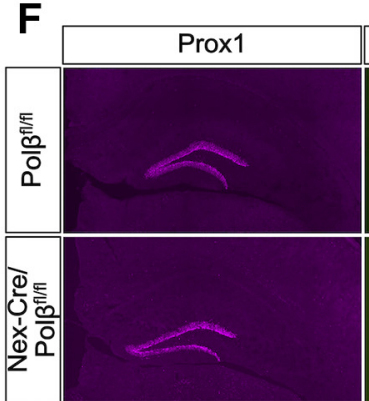

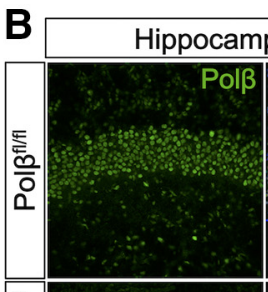
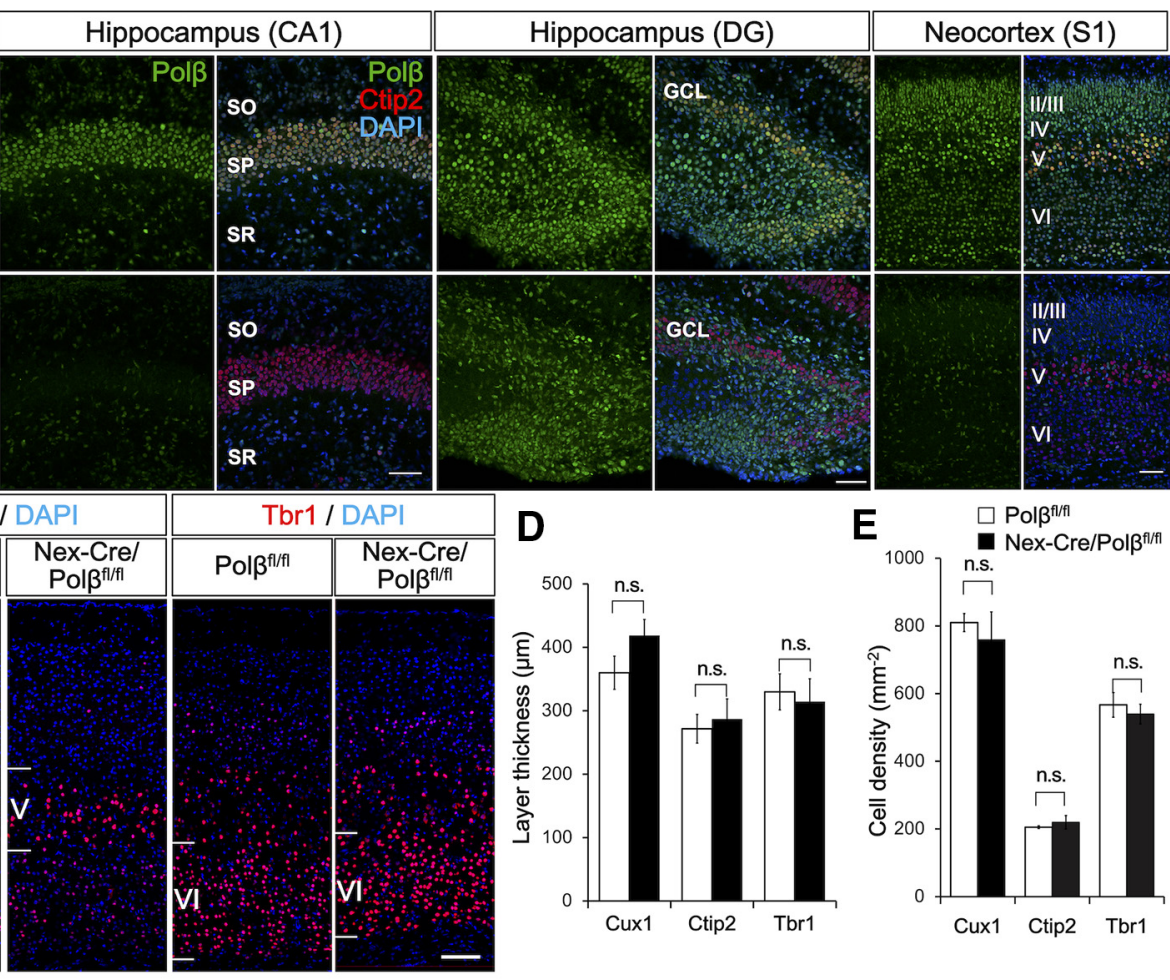

D
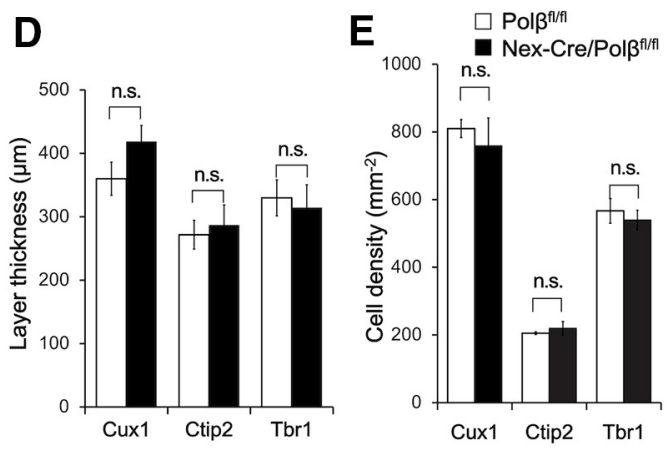

Figure 1. Neocortical and hippocampal cytoarchitecture in Nex-Cre/Pol $\beta^{f / f l}$ mice is comparable with those in $P o l \beta^{f / f f}$. A, Immunohistochemistry was performed with anti-Pol $\beta$ and -Ctip2 antibodies in P2 Nex-Cre/Pol $\beta^{f / f / l}$ and control Pol $\beta^{f / f l l}$ cortex and hippocampus. Scale bar, $400 \mu \mathrm{m}$. B. Magnified images are hippocampal CA1 area, DG area, and neocortical somatosensory area. Scale bars, $100 \mu \mathrm{m}$. C, Immunohistochemistry was performed with anti-Cux1, -Ctip2, and -Tbr1 antibodies in P15 Nex-Cre/Pol $\beta^{f / f l}$ and Pol $\beta^{f / f f}$ cortex. Scale bar, $200 \mu \mathrm{m} . \boldsymbol{D}, \boldsymbol{E}$, Histograms represent quantitative analysis of layer thickness $(\boldsymbol{D})$ and density of labeled cells for each marker $(\boldsymbol{E})$. $\boldsymbol{F}$, Immunohistochemistry was performed with anti-Prox1 and -Ctip2 antibodies in P28 Nex-Cre/Pol $\beta^{f / f}$ and control Pol $\beta^{f / f l}$ hippocampus. Scale bar, $400 \mu \mathrm{m}$. G, ISH was performed using an antisense riboprobe to Gad1 in P15 Nex-Cre/Pol $\beta^{f / f l}$ and control Pol $\beta^{f / / f}$ hippocampus and NCX. SO, Stratum oriens; SR, stratum radiatum; SLM, stratum lacunosum-moleculare; ML, molecular layer. Scale bars, $100 \mu \mathrm{m}$.

probe test was performed without the escape box for $3 \mathrm{~min}$, and time spent around each hole was measured and the ratio of time spent around the target/all holes was quantified.

In conditioning session of contextual and cued fear-conditioning test, each mouse was placed in a transparent acrylic chamber with a stainless-steel grid floor (O'Hara) and allowed to explore for $2 \mathrm{~min}$. White noise $(55 \mathrm{~dB})$ was then presented for $30 \mathrm{~s}$ as a conditioned stimulus. A mild footshock $(0.3 \mathrm{~mA}, 2 \mathrm{~s})$ was presented as an unconditioned stimulus during the last $2 \mathrm{~s}$ of the conditioned stimulus. Three conditioned stimulus-unconditioned stimulus pairings were presented with a 2 min interval. One day or 1 month after the conditioning session, contestual tests were conducted in the same chamber as conditioning. Cued tests with altered context were then conducted in a triangular and white opaque chamber, which was located in a different room. In each test, freezing percentage and distance traveled in $1 \mathrm{~min}$ were quantified.

In the elevated plus maze, each mouse was placed in the central square of the maze, which consisted of two open arms $(25 \times 5 \mathrm{~cm})$ and two closed arms $(25 \times 5 \mathrm{~cm}$, with $15 \mathrm{~cm}$-high transparent walls), and allowed to explore for $10 \mathrm{~min}$. The number of total entries into the arms, percentage of entries into the open arms, and percentage of time spent in the open arms were quantified.
Statistical analysis. In statistical analysis, the number of samples analyzed is given for each experiment. Significant differences were determined with Student's $t$ test, one-way ANOVA with Tukey's post hoc test for multiple comparisons, or repeated-measures ANOVA. All statistical values are presented as mean \pm SEM. All data were analyzed using Excel 2013 (Microsoft), StatView 5.0.1 software (SAS Institute), and EZR (Kanda, 2013).

\section{Results}

Nex-Cre-mediated Pol $\beta$ loss does not affect neocortical or hippocampal cytoarchitecture

To investigate the spatiotemporal role of $\mathrm{Pol} \beta$ in postmitotic neuronal development, we used Nex-Cre/Pol $\beta^{f l f l}$ mice (Onishi et al., 2017). In control Pol $\beta^{f l f l}$ mice, $\operatorname{Pol} \beta$ immunoreactivity was roughly ubiquitous throughout the NCX and the hippocampus at $\mathrm{P} 2$, and its subcellular localization was predominantly nuclear (Fig. $1 A, B$ ). As expected, excitatory glutamatergic neurons, including Ctip2-positive cells, lost $\operatorname{Pol} \beta$ expression in the NCX and hippocampus of Nex-Cre/Pol $\beta^{f l f l}$ mice (Goebbels et al., 
2006) (Fig. $1 A, B$ ). To investigate the impact of $\operatorname{Pol} \beta$ deficiency on neocortical laminar organization, immunohistochemistry with antibodies for layer-specific molecules was performed in Pol $\beta^{f l f l}$ and Nex-Cre/Pol $\beta^{f l f l}$ mice at P15 (Fig. 1C). Anti-Cux1, -Ctip2, and -Tbr1 antibodies were used for layer II-IV, V, and VI markers, respectively (Hevner et al., 2001; Nieto et al., 2004; Arlotta et al., 2005). However, the thickness (Fig. 1D; Cux1: $p=0.1860$, Ctip2: $p=0.7233$, Tbr1: $p=0.7541$, two-tailed Student's $t$ test) and the cell density (Fig. $1 E$; Cux1: $p=0.5890$, Ctip2: $p=0.5142$, Tbr1: $p=0.5747$, two-tailed Student's $t$ test) in each layer were comparable between control Pol $\beta^{f l f l}$ and Nex$\mathrm{Cre} / \mathrm{Pol} \beta^{f l f l}$ mice. Hippocampal CA1, CA3 pyramidal cell layer, and dentate gyrus (DG) cytoarchitecture, revealed by anti-Ctip2 and -Proxl antibodies in Nex-Cre/Pol $\beta^{f l / f l}$ mice, were also similar to those in control Pol $\beta^{f l / f l}$ mice (Fig. $1 F$ ) (Leid et al., 2004; Iwano et al., 2012). In addition, to examine the possibility that the loss of $\mathrm{Pol} \beta$ in glutamatergic excitatory neurons affects GABAergic inhibitory neurons, ISH was performed using an antisense riboprobe specific to Gad1, a marker of GABAergic inhibitory neurons (Feldblum et al., 1993). The distribution of the soma appeared normal in NCX, CA1, and DG in Nex-Crel Pol $\beta^{f l f l}$ mice (Fig. 1G). These results suggest that Nex-Cre-mediated $\operatorname{Pol} \beta$ loss does not affect neocortical and hippocampal cytoarchitecture.

\section{Pol $\beta$-deficient neurons show accumulation of DNA DSBs in postnatal development}

To examine whether $\operatorname{Pol} \beta$ deficiency affects genome stability in neuronal development, DSB formation was investigated at embryonic and postnatal stages by immunohistochemical analysis with an antibody against $\gamma \mathrm{H} 2 \mathrm{AX}$, a DSB marker (Rogakou et al., 1999; Onishi et al., 2017). Multiple strong signals of $\gamma \mathrm{H} 2 \mathrm{AX}$ foci were frequently found in a large number of Nex-Cre/Pol $\beta^{f l f l}$ hippocampal CA1 and CA3 pyramidal cell nuclei at P15, while only a few cells were focus-positive in controls (Fig. 2A,B,E). On the other hand, focus-positive cells were rare in Nex-Cre/Pol $\beta^{f l f l}$ DG granule cells (Fig. $2 C, E$ ), although $\operatorname{Pol} \beta$ expression disappeared in these cells (Goebbels et al., 2006) (Fig. 1A,B). Quantitative analyses of the focus formation showed that both the number of foci in a nucleus and the fraction of focus-positive cells were significantly larger in Nex-Cre/Pol $\beta^{f l f l}$ CA1 and CA3 pyramidal cells, but not DG granule cells, compared with those of the control in Pol $\beta^{f l / f l}$ mice (Fig. $2 G$; stratum pyramidale [SP]: $p<0.001$, granule cell layer [GCL]: $p=0.981$; Fig. $2 H$; SP: $p<0.001$, GCL: $p=0.978$ ). Consistent with these observations, immunostaining with 53BP1, a protein involved in nonhomologous end joining, also showed focus formation in Nex-Cre/Pol $\beta^{f l f l}$ mice (Fig. $2 I, J$ ). 53BP1 foci were predominantly colocalized with $\gamma \mathrm{H} 2 \mathrm{AX}$ foci in the nuclei (Fig. 2K), strongly indicating that the foci were because of DSB formation (Schultz et al., 2000). The developmental time course further demonstrated that $\gamma \mathrm{H} 2 \mathrm{AX}$ foci were undetectable during the embryonic stages (E16.5 and 18.5) and appeared from P2 (Fig. 3A). The signals just peaked at P15 and then decreased until the 3 month adult stage (Fig. $3 A, C, D$ ). Similarly, a fraction of neocortical neurons in Nex-Cre/Pol $\beta^{f l f l}$ mice also exhibited a transient increase of $\gamma \mathrm{H} 2 \mathrm{AX}$ focus formation (Fig. $2 A, D$ ) with a comparable developmental time course (Fig. $3 B, E, F$ ), although the increase was significantly less marked than in hippocampal pyramidal neurons (Fig. $2 E-H$; the mean number of foci in a nucleus was 2.4 in the SP and 0.3 in the NCX; the fraction of $\gamma \mathrm{H} 2 \mathrm{AX}$ focus-positive cells was $79 \%$ in the SP and $20 \%$ in the NCX). These results indicate that $\operatorname{Pol} \beta$ deficiency transiently increases DSB formation during postnatal neuronal development, although the extent of DSBs differs between brain regions.

A next question is whether DSB accumulation induces neuronal apoptosis as observed in Emx1-Cre/Pol $\beta^{f l f l}$ mice (Onishi et al., 2017). Anti-cleaved caspase- 3 immunohistochemistry was performed in Nex-Cre/Pol $\beta^{f l f l}$ mice. Unexpectedly, a few cleaved caspase 3-positive cells were observed in Nex-Cre/Pol $\beta^{f l / f l}$ hippocampus and NCX at P2 and P15, during which DSB formation increases (Fig. $3 G$ ). The abundance of apoptotic cells was similar to that in control Pol $\beta^{f l f l}$ mice (Fig. $3 H, \mathrm{P} 2, \mathrm{CA} 1: p=0.480$, CA3: $p=0.949$, DG: $p=0.628$; P15, CA1: $p=0.408$, CA3: $p=0.753$, DG: $p=0.266$, two-tailed Student's $t$ test; Fig. $3 I, \mathrm{P} 2$ : $p=0.203$, P15: $p=0.703$, two-tailed Student's $t$ test). To confirm this, we further examined neuronal cell density. The values in Nex-Cre/Pol $\beta^{f l f l}$ hippocampus and NCX were similar to those in control Pol $\beta^{\text {flflf }}$ at P15 (Fig. 3J, SP: $p=0.0843$, GCL: $p=0.3436$, NCX: $p=0.2883$, two-tailed Student's $t$ test) and 3 months (Fig. $3 K$, SP: $p=0.7751$, GCL: $p=0.9333$, NCX: $p=0.2033$, two-tailed Student's $t$ test). Together, these results suggest that $\operatorname{Pol} \beta$ deficiency leads to genome instability, but does not affect cell survival, in hippocampal and neocortical neurons during postnatal development.

\section{Pol $\beta$ is required for BER in postmitotic neurons}

$\operatorname{Pol} \beta$ is a key enzyme in BER but not in DSB repair (DSBR) (Wilson et al., 2000). The DSB formation in $\operatorname{Pol} \beta$-deficient neurons may be because of accumulation of single-strand breaks (SSBs) as BER intermediates. To test this possibility, immunohistochemical analysis with an antibody against XRCC1, an SSB marker (El-Khamisy et al., 2003), was performed. Fluorescence intensity of XRCC1 was significantly increased in P15 Nex-Cre/ Pol $\beta^{f l f l}$ hippocampal CA1 pyramidal cell nuclei compared with control Pol $\beta^{f l f l}$ nuclei (Fig. 4A-C; $p=0.0003$, ANOVA with Tukey's post hoc test). In addition, the XRCC1 intensity increased even during normal hippocampal development from P2 to P15 (Fig. 4A,C; Pol $\beta^{f l f f}: p<0.0001$, Nex-Cre/Pol $\beta^{f l f l}: p<0.0001$, ANOVA with Tukey's post hoc test), similar to developmental changes of the $\gamma \mathrm{H} 2 \mathrm{AX}$ foci in Nex-Cre/Pol $\beta^{f l / f l}$ mice (Fig. 3). These results suggest the possibility that an abnormal level of SSBs in $\mathrm{Nex}-\mathrm{Cre} / \mathrm{Pol} \beta^{\text {flfl }}$ mice leads to DSB formation.

The sensitivity of $\operatorname{Pol} \beta$-deficient neurons to specific DNAdamaging agents was examined to reveal the role of $\operatorname{Pol} \beta$ in BER and DSBR. Primary cultured neurons from E16.5 control or Nex$\mathrm{Cre} / \mathrm{Pol} \beta^{f l / f l}$ mouse NCX were treated with MMS, which induces base damage (Beranek, 1990), or etoposide, an inhibitor of topoisomerase II that induces DSBs (Ross et al., 1984). $\operatorname{Pol} \beta$-deficient neurons showed higher sensitivity to MMS than control (Fig. $4 D$, $E ; p=0.0190$, repeated-measures ANOVA). In contrast, there was no significant difference following the etoposide treatment (Fig. $4 D, E ; p=0.96282$, repeated-measures ANOVA). In addition, $\gamma \mathrm{H} 2 \mathrm{AX}$ focus formation after MMS treatment was significantly increased in neuronal cultures from $\mathrm{Nex}-\mathrm{Cre} / \mathrm{Pol} \beta^{f l f l}$ mice compared with those from Pol $\beta^{f l f l}$ mice (Fig. $4 F, G ; P o l \beta^{f l f l}$ vs NexCre/Pol $\beta^{f l / f l}, p<0.0001$, ANOVA with Tukey's post hoc test; Fig. $4 H ; P o l \beta^{f l / f l}$ vs Nex-Cre/Pol $\beta^{f l / f l}, p=0.0304$, ANOVA with Tukey's post hoc test). Together, these results demonstrate that $\operatorname{Pol} \beta$ is required for BER rather than DSBR, suggesting that highly accumulated SSBs are converted to DSBs in $\operatorname{Pol} \beta$-deficient neurons during postnatal development.

\section{Loss of Pol $\beta$ in active DNA demethylation causes DSBs in developing hippocampal CA1 neurons}

To examine the possibility that active DNA demethylation was a cause of the DSB formation in $\operatorname{Pol} \beta$-deficient neurons during 


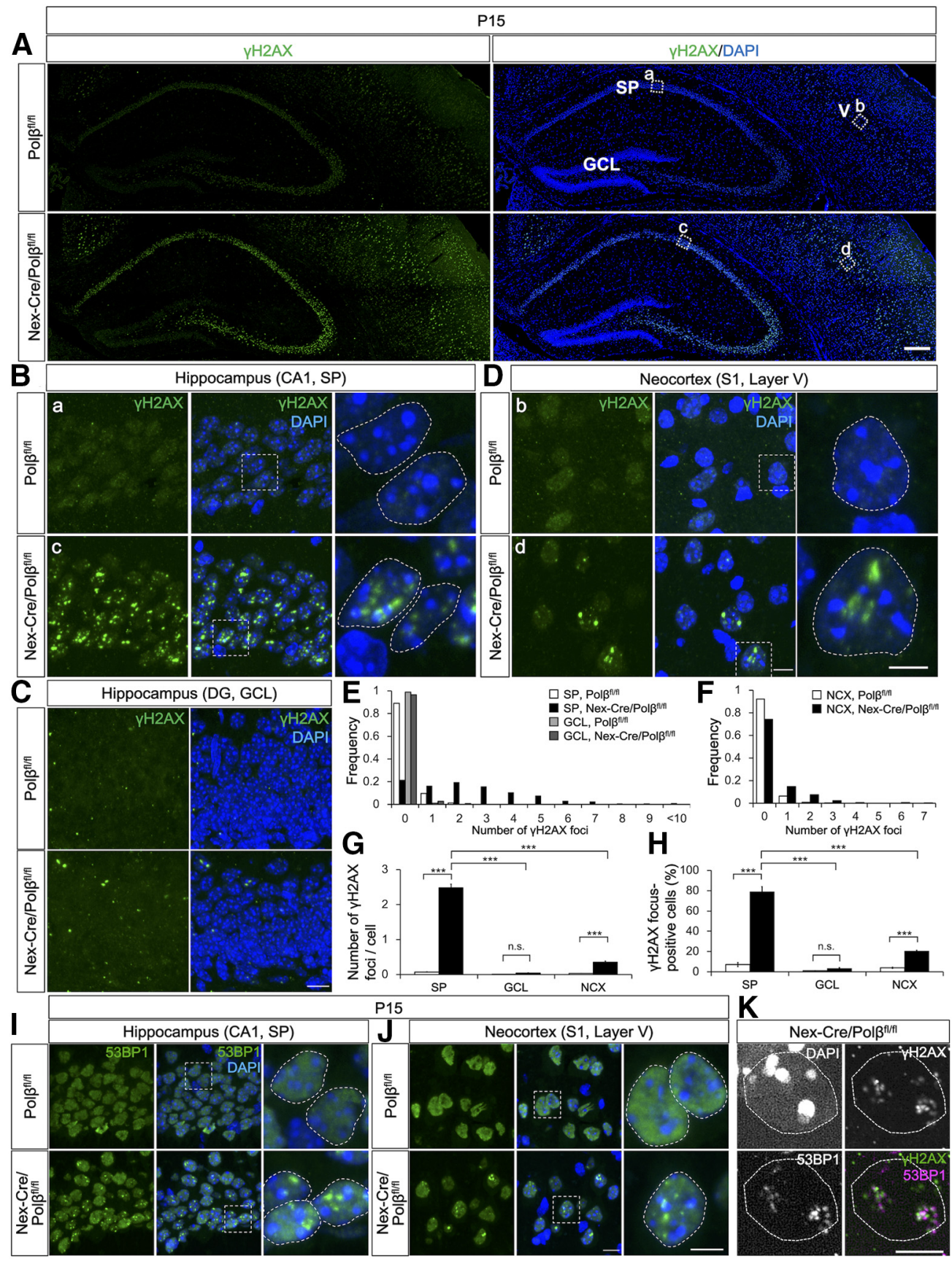

Figure 2. Nex-Cre/Pol $\beta^{f / f}$ mice exhibit DSBs in postnatal hippocampus and NCX. A, Immunohistochemistry was performed with anti- $\gamma \mathrm{H} 2 \mathrm{AX}$ antibody in $\mathrm{P} 15 \mathrm{Nex}-\mathrm{Cre} / \mathrm{Pol} \beta^{\mathrm{f} / \mathrm{fl}}$ and $\mathrm{Pol} \beta^{\mathrm{f} / \mathrm{fl}}$ hippocampus and NCX. Scale bar, $400 \mu \mathrm{m}$. B, D, Magnified images of the boxed areas in $\boldsymbol{A}$, including hippocampal CA1 pyramidal cell layer (a, c) and neocortical layer V (b, d) are shown. Magnified images of the dashed-line boxed areas in the middle image are shown in the rightmost images. Dashed lines in the rightmost images indicate the perimeter of the nucleus. Scale bars: middle, $10 \mu \mathrm{m}$; right, $5 \mu \mathrm{m}$. C, Immunohistochemistry was performed with anti- $\gamma \mathrm{H} 2 \mathrm{AX}$ antibody in P15 hippocampal DG GCL. Scale bar, $10 \mu \mathrm{m} . \boldsymbol{E}, \boldsymbol{F}$, Distribution histogram shows the number of $\gamma \mathrm{H} 2 \mathrm{AX}$ foci in P15 Nex-Cre/Pol $\beta^{\mathrm{fl} / f / f}$ and Pol $\beta^{\mathrm{f} / \mathrm{fl}} \mathrm{SP}, \mathrm{GCL}(\boldsymbol{E})$, and NCX (F). G, H, Histograms represent quantitative analysis of the mean number of $\gamma \mathrm{H} 2 \mathrm{AX}$ foci in each nucleus $(\boldsymbol{G})$ and percentage of $\gamma$ H2AX focus-positive cells $(\boldsymbol{H})$ in SP, GCL, and NCX of Nex-Cre/Pol $\beta^{f / f / f}\left(n=492, n=765, n=690\right.$ cells) and Pol $\beta^{f / f / f}(n=513, n=792, n=791$ cells) mice. Data are the mean \pm SEM from three different brains. $* * * p<0.001$ (ANOVA with Tukey's post hoc test). I, J, Immunohistochemistry was performed with rabbit anti-53BP1 antibody in P15 Nex-Cre/ $P o l \beta^{f / f l}$ and $P o l \beta^{f / f l}$ SP $(I)$ and NCX (J). Magnified images of the boxed areas are shown in the right panels. Dashed lines in the rightmost images indicate the perimeter of the nucleus. Scale bars: middle, $10 \mu \mathrm{m}$; right, $5 \mu \mathrm{m}$. $\boldsymbol{K}$, Immunohistochemistry was performed with rat anti-53BP1 and rabbit anti- $\gamma \mathrm{H} 2 \mathrm{AX}$ antibodies in P15 Nex-Cre/Pol $\beta^{\text {fl/fl }}$ SP. Scale bar, $10 \mu \mathrm{m}$.

postnatal development (Lister et al., 2013; Sharma et al., 2016; $\mathrm{Wu}$ and Zhang, 2017), developmental changes in $5 \mathrm{mC}$ and 5 hmC levels were quantified between P2 and P28. Immunoblot analysis with specific antibodies revealed that both $5 \mathrm{mC}$ and 5 hmC levels decreased strongly in control Pol $\beta^{f l f l}$ hippocampus between P2 and P15 (Fig. 5A,B), during which the extent of SSB and DSB formation increased in hippocampal pyramidal neurons (Figs. 3, 4A-C). Consistent with this, immunohistochemical analysis also showed a decrease of $5 \mathrm{mC}$ level in CA1 pyramidal neurons but not in DG granule cells, in which $\gamma \mathrm{H} 2 \mathrm{AX}$ foci were rare (Fig. $5 C, D$ ). These results suggest that much active DNA demethylation occurs on the genome of hippocampal pyramidal cells during this period.

We examined whether inhibition of the active DNA demethylation process could affect DSB formation in $\operatorname{Pol} \beta$-deficient hippocampal pyramidal neurons in vivo. Overexpression of microRNAs 

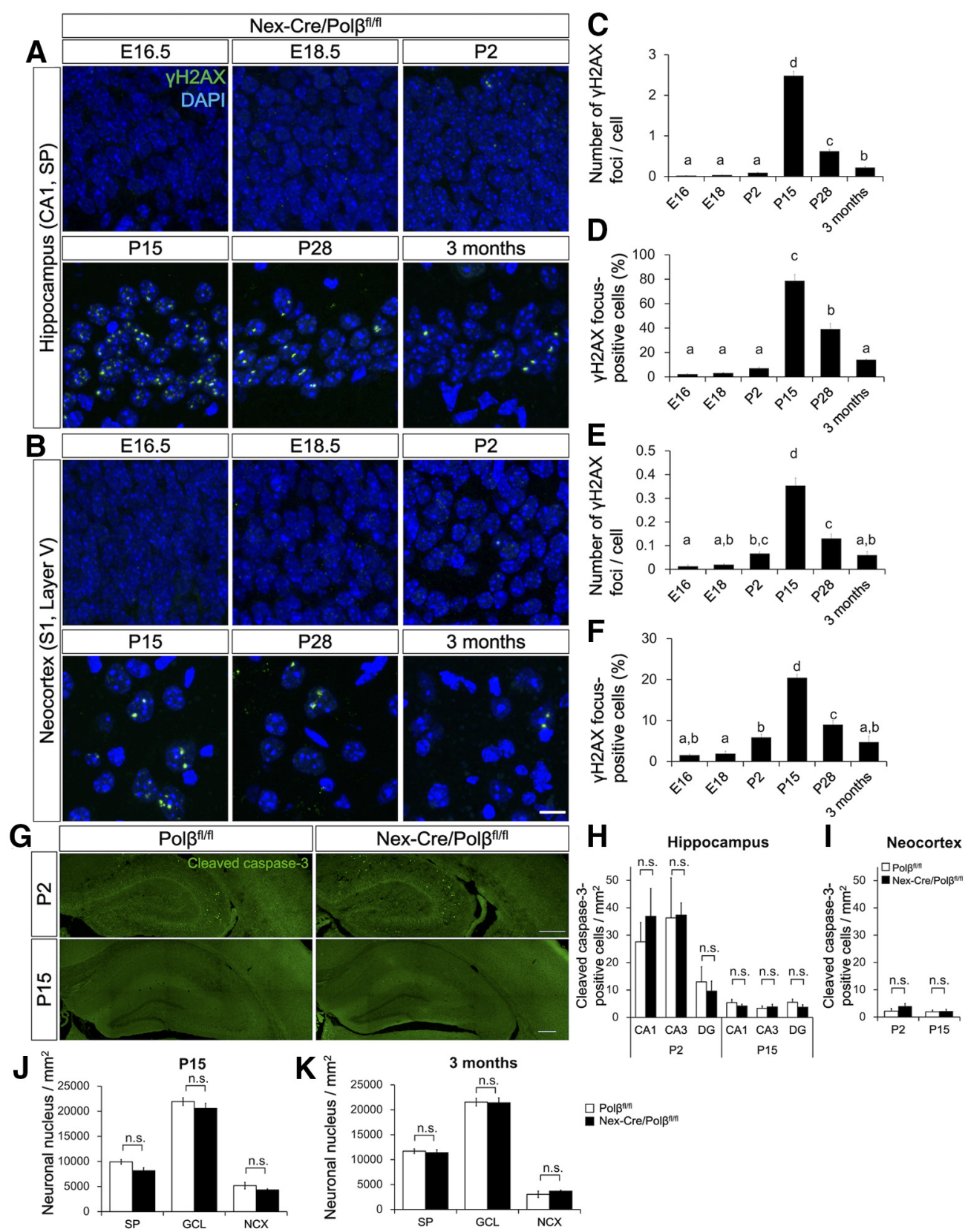

Figure 3. DSB formation in Nex-Cre/Pol $\beta^{f / f f}$ mice transiently increases during postnatal development. $\boldsymbol{A}, \boldsymbol{B}$, Immunohistochemistry was performed with anti- $\gamma \mathrm{H} 2 \mathrm{AX}$ antibody in Nex-Cre/ $\mathrm{Pol} \beta^{f / f l}$ and Pol $\beta^{f / f l} \mathrm{SP}(\boldsymbol{A})$ and NCX (B) at E16.5, E18.5, P2, P15, P28, and 3 months. Scale bar, $10 \mu \mathrm{m}$. $\mathbf{C}-\boldsymbol{F}$, Histograms represent quantitative analysis of the mean number of $\gamma \mathrm{H} 2 \mathrm{AX}$ foci in each nucleus $(\boldsymbol{C}, \boldsymbol{E})$ and $\gamma$ H2AX focus-positive cells $(\boldsymbol{D}, \boldsymbol{F})$ in SP $(\boldsymbol{C}, \boldsymbol{D})$, and NCX $(\boldsymbol{E}, \boldsymbol{F})$ of Nex-Cre/Pol $\beta^{f / f t}$ mice at E16.5 $(n=1756$ cells), E18.5 ( $n=1199$ cells), P2 ( $n=1160$ cells), P15 ( $n=492$ cells), P28 ( $n=477$ cells), and 3 months $(n=505$ cells). Data are the mean \pm SEM from three independent experiments. Different letters indicate significant differences between groups: $p<0.05$, ANOVA with Tukey's post hoc test. G, Immunohistochemistry was performed with anti-cleaved caspase-3 antibody in Nex-Cre/Pol $\beta^{f / f l}$ and $P$ ol $\beta^{f / f l}$ hippocampus and cortex at P2 and P15. Scale bar, $400 \mu \mathrm{m} . \boldsymbol{H}, \boldsymbol{I}$, Histograms represent quantitative analysis of cleaved caspase-3-positive cell density in Nex-Cre/Pol $\beta^{f / f l}$ and $P$ ol $\beta^{f / f l}$ hippocampus $(\boldsymbol{H})$ and NCX $(\boldsymbol{I})$. Data are the mean \pm SEM from three different brains. J, $\boldsymbol{K}$, Histograms represent quantitative analysis of neuronal nucleus density in Nex-Cre/Pol $\beta^{f / / f}$ and $P$ ol $\beta^{f / f l}$ SP, GCL, and NCX at P15 $(\boldsymbol{J})$ and 3 months $(\boldsymbol{K})$. Data are the mean \pm SEM from three different brains.

miR-29a and miR-29b-1 has been reported to inhibit expression of several genes involved in DNA methylation and demethylation processes, resulting in a decrease in $5 \mathrm{hmC}$ level in transfected cells (Cheng et al., 2013; Hysolli et al., 2016). The miRNA expression vector was transfected into CA1 neurons in Nex-Cre/Pol $\beta^{f l / f l}$ hippocampus using an in utero electroporation technique. miR-29a/b-1 efficiently decreased the $5 \mathrm{hmC}$ level in the transfected neurons (Fig. 6A). The numbers of $\gamma \mathrm{H} 2 \mathrm{AX}$ foci and of focus-positive cells were significantly lower in the transfected neurons than in the surrounding untransfected neurons of P15 Nex-Cre/Pol $\beta^{f l / f l}$ hippocampus (Fig. $6 B, C, p<0.0001$, Kolmogorov-Smirnov test; Fig. $6 D$, $p<0.0001$, two-tailed Student's $t$ test; Fig. $6 E, p=0.0175$, twotailed Student's $t$ test), indicating that inhibition of active DNA demethylation suppresses DSB formation.

Conversely, we tested whether induction of active demethylation promotes DSB formation in $\operatorname{Pol} \beta$-deficient neurons. TET1CD, which induces $5 \mathrm{hmC}$ more efficiently than full-length TET1 (Tahiliani et al., 2009), was overexpressed in neocortical neurons using in utero electroporation. As expected, the $5 \mathrm{hmC}$ 


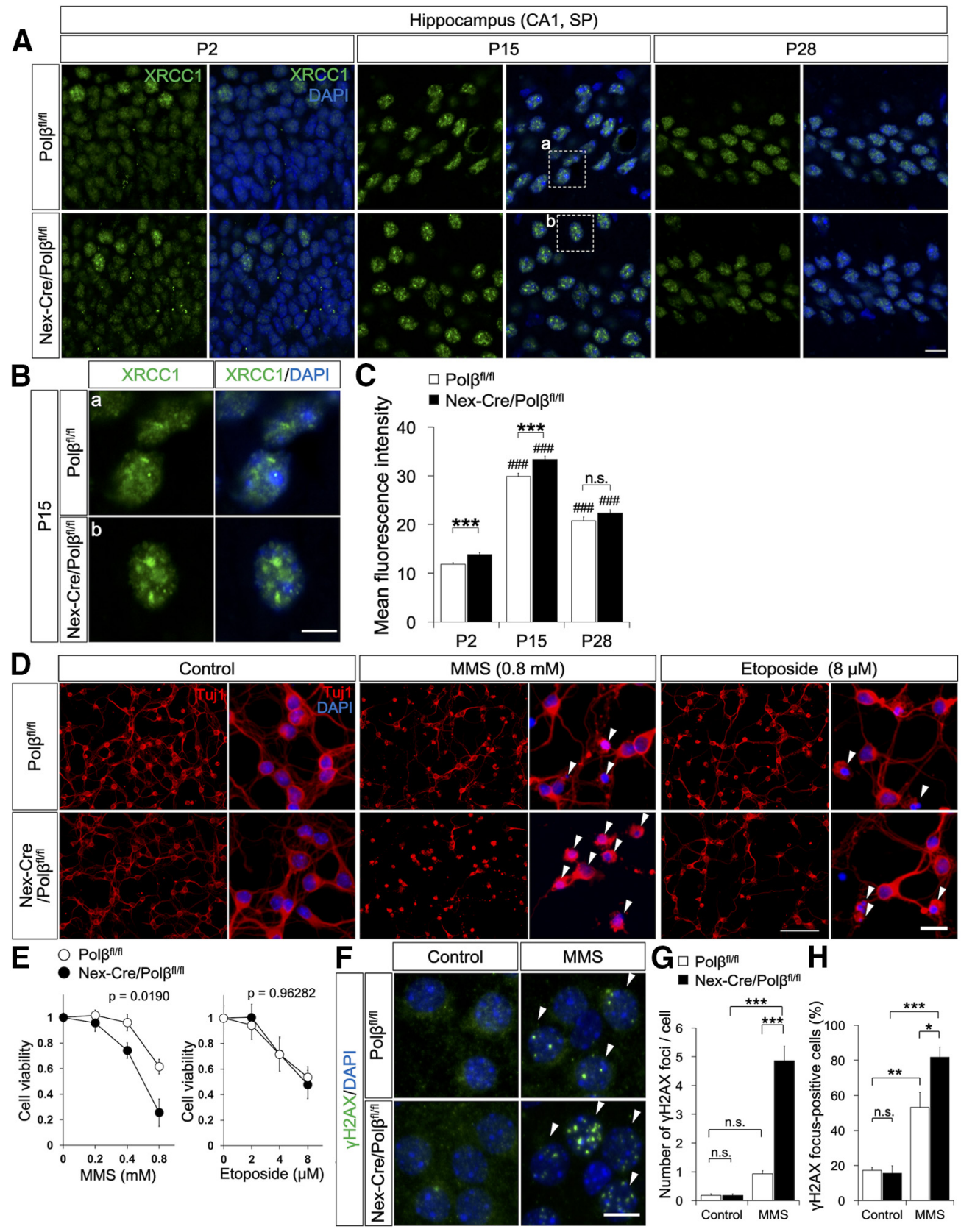

Figure 4. $\operatorname{Pol} \beta$ is required for BER rather than DSBR in CA1 pyramidal neurons. $A$, Immunohistochemistry was performed with anti-XRCC1 antibody in CA1 pyramidal cell layers of Nex-Cre/ $P o l \beta^{f / f f}$ and Pol $\beta^{f / f l}$ hippocampus at P2, P15, and P28. Scale bar, $10 \mu \mathrm{m}$. B, Magnified images of the boxed areas in $\boldsymbol{A}$ are shown. Scale bar, $5 \mu \mathrm{m}$. $\boldsymbol{C}$, Histogram represents the mean XRCC1 fluorescence intensity in DAPI-stained nuclei of Nex-Cre/Pol $\beta^{f / / f l}\left(n=576, n=295\right.$, and $n=234$ cells) and Pol $\beta^{f / / f}$ ( $n=643, n=282$, and $n=256$ cells) hippocampal CA1 cells at P2, P15, and P28. Data are the mean \pm SEM. Significant difference from Pol $\beta^{A / f / 1}$ mice: $* * * p<0.001$ (ANOVA with Tukey's post hoc test). Significant difference between age groups: ${ }^{\# \# \# ~} p<0.001$ (ANOVA with Tukey's post hoc test). D, Primary cultured neurons from E16.5 Nex-Cre/Pol $\beta^{f / f f}$ or Pol $\beta^{f / / f} \mathrm{NCX}$ were treated with MMS or etoposide for $1 \mathrm{~h}$ at 3-4 DIV, and fixed after $24 \mathrm{~h}$ recovery. Immunocytochemistry was then performed with anti-Tuj1 antibody. Arrowheads indicate dying pyknotic cells. Magnified images are shown in the right panels. Scale bars: $100 \mu \mathrm{m}$, $20 \mu \mathrm{m}$. E, Quantitative analysis of cell viability of Nex-Cre/Pol $\beta^{\mathrm{f} / / \mathrm{f}}$ and $\mathrm{Pol} / \beta^{\mathrm{f} / \mathrm{fl}}$ neocortical neurons treated with MMS or etoposide for $1 \mathrm{~h}$. Data are mean \pm SEM from three independent experiments. Significant difference: $p$ values (repeated-measures ANOVA) are indicated. $F$, Primary cultured neurons from E16.5 Nex-Cre/Pol $\beta^{f / / f}$ or Pol $\beta^{f / / f l}$ NCX were treated with MMS for 1 $\mathrm{h}$ at 14 DIV and immunocytochemistry was performed with anti- $\gamma \mathrm{H} 2 \mathrm{AX}$ antibody. Arrowheads indicate $\gamma \mathrm{H} 2 \mathrm{AX}$ focus-positive cells. $\boldsymbol{G}, \boldsymbol{H}$, Histograms represent quantitative analysis of the mean number of $\gamma \mathrm{H} 2 \mathrm{AX}$ foci in each nucleus $(\boldsymbol{G})$ and the percentage of $\gamma \mathrm{H} 2 \mathrm{AX}$ focus-positive cells $(\boldsymbol{H})$. Data are mean \pm SEM from control or MMS-treated Nex-Cre/Pol $\beta^{f / f / f}(n=79$ cells, $n=80$ cells) and $P o l \beta^{f / f f l}(n=71$ cells, $n=86$ cells) neurons in three independent experiments. $* p<0.05 ; * * p<0.01 ; * * * p<0.001$; ANOVA with Tukey's post hoc test.

level increased in both the transfected Pol $\beta^{f l f l}$ and Nex-Cre/ Pol $\beta^{f l / f l}$ cortical neurons at P7 (Fig. $6 F$ ). The $\gamma \mathrm{H} 2 \mathrm{AX}$ foci were increased in the transfected neurons compared with the untransfected neurons of Nex-Cre/Pol $\beta^{f l f l}$ NCX, but not of Pol $\beta^{f l / f l}$ NCX (Fig. 6G). Quantitative analysis also demonstrated that both parameters of $\gamma \mathrm{H} 2 \mathrm{AX}$ foci were significantly increased in the transfected neurons relative to the surrounding neurons in
Nex-Cre/Pol $\beta^{f l f l}$ NCX (Fig. $6 H$, GFP(-) vs GFP(+), Pol $\beta^{f l / f l}$ : $p=0.9883$, Nex-Cre/Pol $\beta^{\text {flf } t:} p<0.0001$, ANOVA with Tukey's post hoc test; Fig. 6I, GFP(-) vs GFP(+), Pol $\beta^{f l f l}: p=1.0000$; Nex-Cre/Pol $\beta^{f l f f}: p<0.0001$, ANOVA with Tukey's post hoc test), indicating that induction of active DNA demethylation is sufficient to promote DSB formation in $\operatorname{Pol} \beta$-deficient cortical neurons. 
A

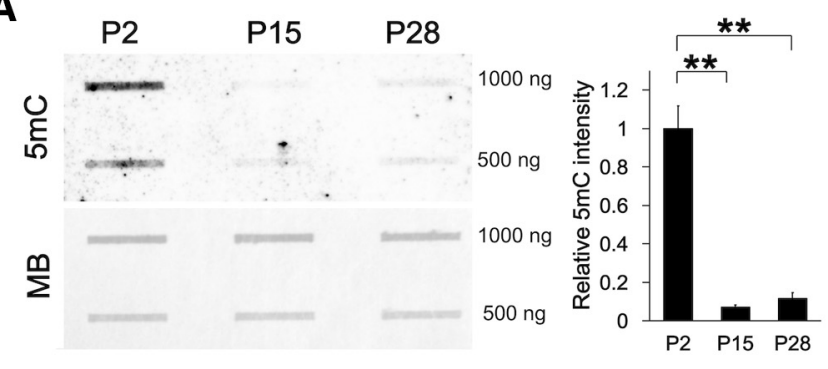

B

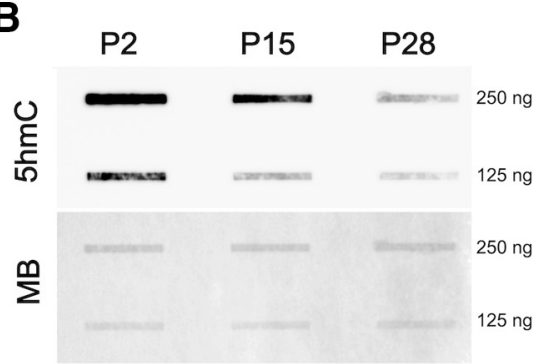

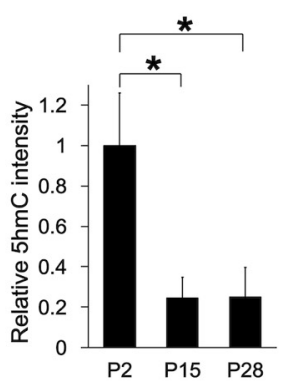
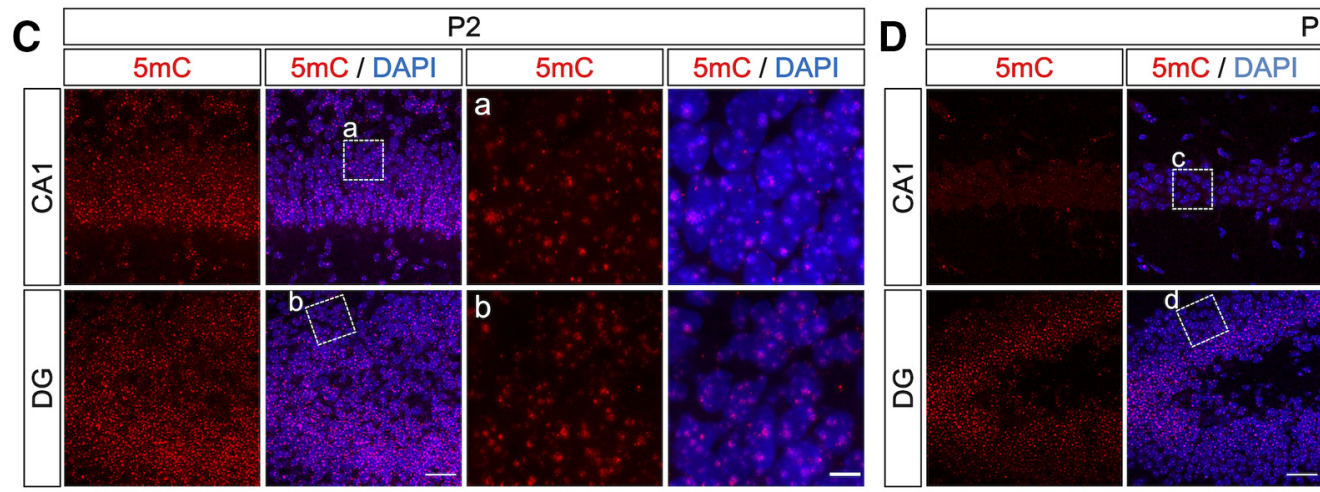

P15

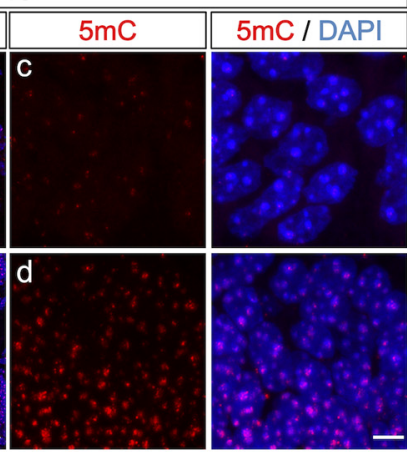

Figure 5. Developmental change of DNA methylation level in hippocampus. $\boldsymbol{A}, \boldsymbol{B}$, Immunoblot analyses show amounts of $5 \mathrm{mC}(\boldsymbol{A})$ and $5 \mathrm{hmC}(\boldsymbol{B})$ in genomic DNA from P2, P15, and P28 Pol $\beta^{f / f l}$ hippocampus. The membranes were also stained with methylene blue (MB) as a loading control. The relative intensity of $5 \mathrm{mC}$ and $5 \mathrm{hmC}$ was quantified. Data are mean $\pm \mathrm{SEM}$ from three different brains. $* p<0.05 ; * * p<0.01$, ANOVA with Tukey's post hoc test. C, D, Immunohistochemistry was performed with anti-5mC antibody in CA1 and DG of Pol $\beta^{f / / f}$ hippocampus at P2 $(\boldsymbol{C})$ and P15 (D). Magnified images of the boxed areas including pyramidal cell layer in CA1 (a, c) and GCL in DG (b, d) are shown in the right panels. Scale bars: left, $50 \mu \mathrm{m}$; right, $10 \mu \mathrm{m}$.

Finally, to modulate the endogenous active DNA demethylation process, cultured neocortical neurons from E16.5 Nex-Cre/ Pol $\beta^{f l / f l}$ and $P o l \beta^{f l f l}$ mice were treated with vitamin C, which induces TET1 activity (Blaschke et al., 2013). Immunocytochemistry with anti-5hmC antibody showed an apparent increase in $5 \mathrm{hmC}$ level following $24 \mathrm{~h}$ vitamin $\mathrm{C}$ treatment in both control and $\operatorname{Pol} \beta$ deficient neuronal nuclei (Fig. 6J). Analysis of the DSB formation under this culture condition demonstrated that both the number of $\gamma \mathrm{H} 2 \mathrm{AX}$ foci and the proportion of focus-positive cells were significantly increased in Nex-Cre/Pol $\beta^{f l f l}$ neurons but not in controls (Fig. 6K,L, control vs VitC, Pol $\beta^{f l / f l}: p=0.9932$, Nex-Cre/ Pol $\beta^{f l f l}: p<0.0001$, ANOVA with Tukey's post hoc test; Fig. $6 M$, control vs VitC, Pol $\beta^{f l f l}: p=1.0000$, Nex-Cre $/$ Pol $\beta^{\text {fl/fi: }}$ : $p=0.0001$, ANOVA with Tukey's post hoc test). Together, these results suggest that active DNA demethylation is a primary cause of DSB formation in $\operatorname{Pol} \beta$-deficient neurons during postnatal development.

\section{Pol $\beta$ deficiency affects gene expression and dendrite morphology of hippocampal neurons during postnatal development}

To investigate the possibility that active DNA demethylation defects and/or DSB formation alter gene expression in $\operatorname{Pol} \beta$-deficient neurons, RNA-seq analysis was performed with RNA extracted from P15 control Pol $\beta^{f l f l}$ and Nex-Cre/Pol $\beta^{f l / f l}$ hippocampus. Overall, 219 genes were found to be downregulated, and 199 upregulated, in the Nex-Cre/Pol $\beta^{f l f l}$ hippocampus compared with the control (Fig. $7 A ; n=3, p<0.05$, fold change $>1.2$ ). A functional annotation analysis of these 418 DEGs was performed using Ingenuity Pathway Analysis (IPA) software (Fig. $7 B-G$ ). Genes related to nervous system development and function $\left(p=1.41 \times 10^{-2}\right)$ and to neurologic diseases $\left(p=1.26 \times 10^{-4}\right)$, in addition to cancer, were significantly enriched in the DEGs (Fig.
$7 B, C)$. In the canonical pathways identified by the IPA, signaling pathways related to cell cycle regulation, DNA damage response, and cancer cells were primarily suggested (Fig. 7D), which may reflect a response to DSB formation in $\operatorname{Pol} \beta$-deficient neurons. In addition, among the top hits, the assembly of RNA polymerase I complex $(p=0.012)$, the opioid signaling pathway $(p=0.013)$, and the Wnt/Ca+ pathway $(p=0.016)$, which are known to relate to neuronal development and learning and memory in the hippocampus, were included (Williams et al., 2001; Inestrosa and Varela-Nallar, 2015; Capitano et al., 2016). These results indicate that $\operatorname{Pol} \beta$ deficiency affects the regulation of genes involved in neuronal development and function. Furthermore, a marked similarity was identified in the gene expression profiles between the Pol $\beta$-deficient hippocampus and TET3 shRNA-transfected hippocampal neurons (Yu et al., 2015) using Illumina correlation engine software (Fig. $7 H$; positive correlation: up and up, 9 genes, $p=0.0026$, down and down, 34 genes, $p=0.0030$; negative correlation: up and down, 20 genes, $p=0.1957$, down and up, 13 genes, $p=0.0094$, Fisher's exact test), suggesting that some of the overlapped genes are under the control of active DNA demethylation.

The altered gene expression in the Nex-Cre/Pol $\beta^{f l f l}$ hippocampus may affect development of hippocampal neurons. Dendritic morphology of CA1 pyramidal neurons was examined in the Nex$\mathrm{Cre} / \mathrm{Pol} \beta^{f l f l}$ and $\mathrm{Pol} \beta^{f l f l}$ hippocampus. To visualize the morphology of individual neurons, sparse cell labeling was performed with the Supernova system using in utero electroporation (Luo et al., 2016). While both apical and basal dendrites of Nex-Cre/Pol $\beta^{f l / f l}$ CA1 neurons appeared to be similar to those in the control (Fig. $8 A)$, dendritic width $\left(\mathrm{Pol}^{\mathrm{fl} / \mathrm{fl}}\right.$ vs Nex-Cre/Pol $\beta^{f l / f l} ; 301 \pm 28 \mu \mathrm{m}$, $228 \pm 13 \mu \mathrm{m}, p=0.0204$, ANOVA) and total dendrite length $\left(\right.$ Pol $^{\text {fl/fl }}$ vs Nex-Cre/Pol $\beta^{f l f l} ; 4775 \pm 263 \mu \mathrm{m}, 3997 \pm 207 \mu \mathrm{m}$, $p=0.0248$, ANOVA) were significantly lower in Nex-Cre/Pol $\beta^{f l / f l}$ 

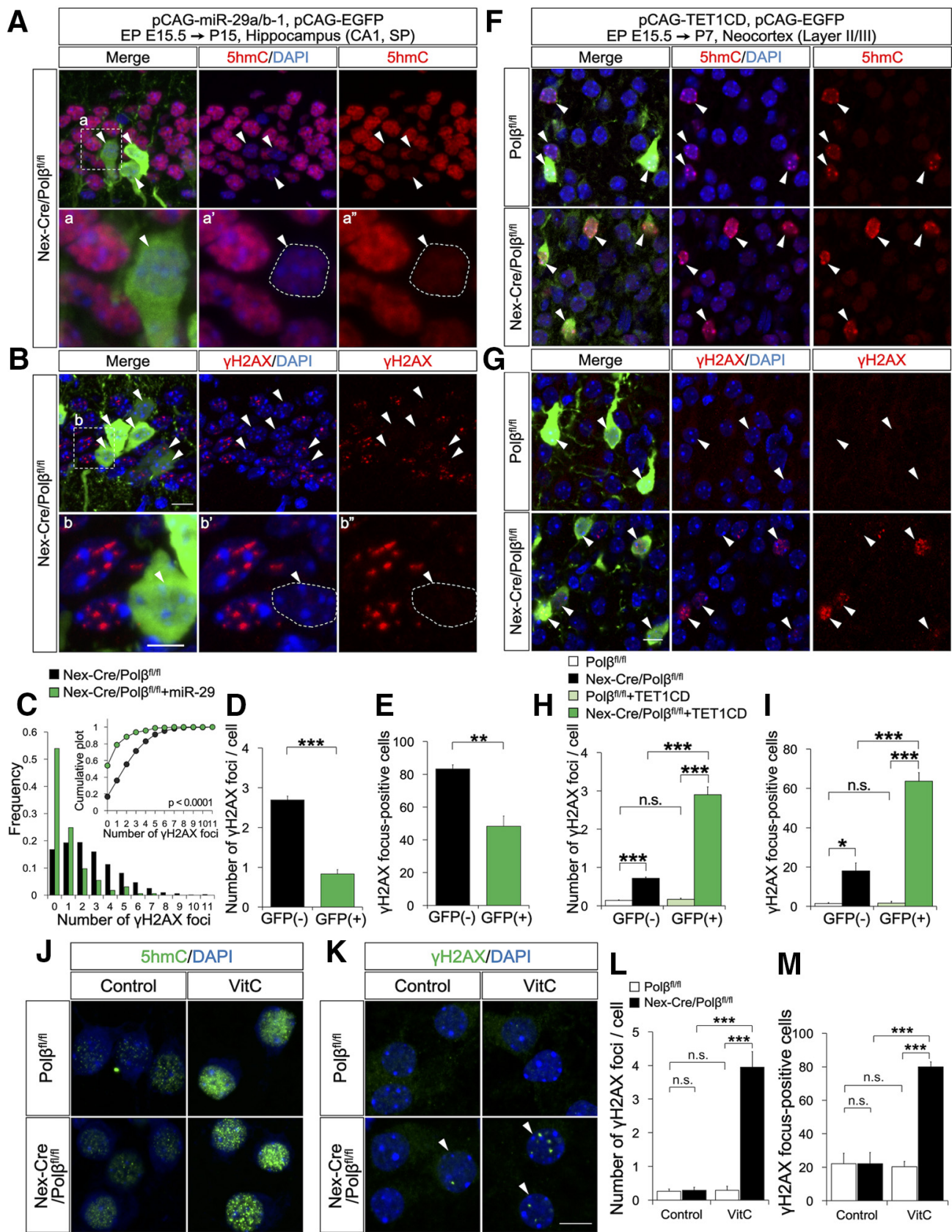

$$
\text { - Nex-Cre/Pol } \beta^{\text {fn/fi }}
$$

$\square$ Pol $\beta^{\text {fllit }}+T E T 1 C D$

$E$
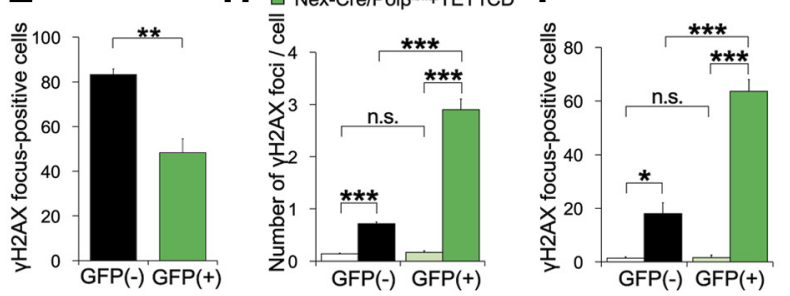

M

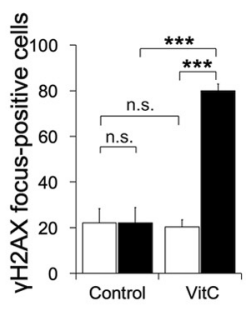

Figure 6. Loss of $\mathrm{Pol} \beta$ in active DNA demethylation causes DSBs in CA1 pyramidal neurons. $\boldsymbol{A}-\boldsymbol{E}$, Hippocampal CA1 neurons were cotransfected with pCAG-miR29a/b-1 and pCAG-EGFP by in utero electroporation at E15.5 and analyzed at P15. Immunohistochemistry was performed with anti-5hmC $(\boldsymbol{A})$, anti- $\gamma \mathrm{H} 2 \mathrm{AX}(\boldsymbol{B})$, and anti-GFP antibodies in Nex-Cre/Pol $\beta^{f / / f}$ hippocampus. $\boldsymbol{A}, \boldsymbol{B}$, Magnified images of the dashed-line boxed areas in the top image are shown in the bottom images. Dashed lines in the bottom images indicate the perimeter of the nucleus. Arrowheads indicate EGFP-positive transfected cells. Scale bars: top, $10 \mu \mathrm{m}$; bottom, $5 \mu \mathrm{m}$. C, Distribution histogram represents the number of $\gamma H 2 \mathrm{AX}$ foci in the transfected (GFP( + ), $n=137$ cells) and the surrounding untransfected (GFP(-), $n=522$ cells) nuclei of Nex-Cre/Pol $\beta^{\text {fl/ff }}$ hippocampus. The Kolmogorov-Smirnov test shows the significant difference between GFP $(-)$ and GFP(+) cells. $\boldsymbol{D}, \boldsymbol{E}$, Histograms represent the average number of $\gamma \mathrm{H} 2 \mathrm{AX}$ foci $(\boldsymbol{D})$ and percentage of focus-positive cells $(\boldsymbol{E})$ in the GFP $(+)$ and the surrounding GFP(-) nuclei of NexCre/Pol $\beta^{f / f f}$ CA1 cells. Data are the mean \pm SEM from three different brains. $* * p<0.01 ; * * * p<0.001$; Student's $t$ test. $\boldsymbol{F}$-I, Neocortical upper layer neurons were cotransfected with pCAG-TET1CD and pCAG-EGFP by in utero electroporation at E15.5 and analyzed at P7. Immunohistochemistry was performed with anti-5hmC $(\boldsymbol{F})$, anti- $\gamma$ H2AX (G), and anti-GFP antibodies in $\mathrm{Nex}-\mathrm{Cre} / \mathrm{Pol} \beta^{f / f t}$ and Pol $\beta^{f / f f} \mathrm{NCX}$. Arrowheads indicate EGFP-positive transfected cells. Scale bar, $10 \mu \mathrm{m}$. $\boldsymbol{H}, \boldsymbol{I}$, Histograms represent the average number of $\gamma \mathrm{H} 2 \mathrm{AX}$ foci $(\boldsymbol{H})$ or percentage of focus-positive cells $(I)$ in the GFP( + ) and surrounding GFP(-) nuclei of Nex-Cre/Pol $\beta^{f / f}\left(n=160\right.$ cells, $n=950$ cells) and Pol $\beta^{f / f l}$ ( $n=161$ cells, $n=966$ cells) NCX. Data are the mean \pm SEM from three different brains. $* p<0.05 ; * * p<0.01 ; * * * p<0.001$; ANOVA with Tukey's post hoc test. $J, K$, Primary cultured neocortical neurons from E16.5 Nex-Cre/Pol $\beta^{\mathrm{f} / f / \mathrm{f}}$ or Pol $\beta^{f / / f}$ mice were treated with vitamin C (VitC) for $24 \mathrm{~h}$ at $14 \mathrm{DIV}$, and immunocytochemistry was performed with anti-5hmC ( $)$ or anti- $\gamma \mathrm{H} 2 \mathrm{AX}(\boldsymbol{K})$ antibodies. Arrowheads indicate $\gamma \mathrm{H} 2 \mathrm{AX}$ focus-positive cells. $L, M$, Histograms represent the mean number of $\gamma \mathrm{H} 2 \mathrm{AX}$ foci in each nucleus $(\boldsymbol{L})$ and the percentage of $\gamma \mathrm{H} 2 \mathrm{AX}$ focus-positive cells $(M)$. Data are the mean \pm SEM from control or VitC-treated Nex-Cre/Pol $\beta^{f / f l}\left(n=48\right.$ cells, $n=62$ cells) and Pol $\beta^{f / f}$ ( $n=54$ cells, $n=49$ cells) neocortical neurons in three independent experiments. $* * * p<0.001$ (ANOVA with Tukey's post hoc test).

than in Pol $\beta^{f l f l}$ neurons (Fig. $8 B$ ). Sholl analysis further revealed that $P o l \beta^{f l f l}$ deficiency resulted in decreased complexity of the distal apical dendrites but not of the basal dendrites (Fig. 8C; apical: $p=0.0173$; basal: $p=0.9717$, repeated-measures ANOVA).
Dendritic spine densities in Nex-Cre/Pol $\beta^{\mathrm{f} / \mathrm{fl}}$ were similar to those in $P o l \beta \beta^{\mathrm{fl} / \mathrm{fl}}$ (Fig. $8 D, E ; p=0.9387$, two-tailed Student's $t$ test). Together, these results suggest that $\operatorname{Pol} \beta$ is required for dendrite formation in the developing hippocampus. 


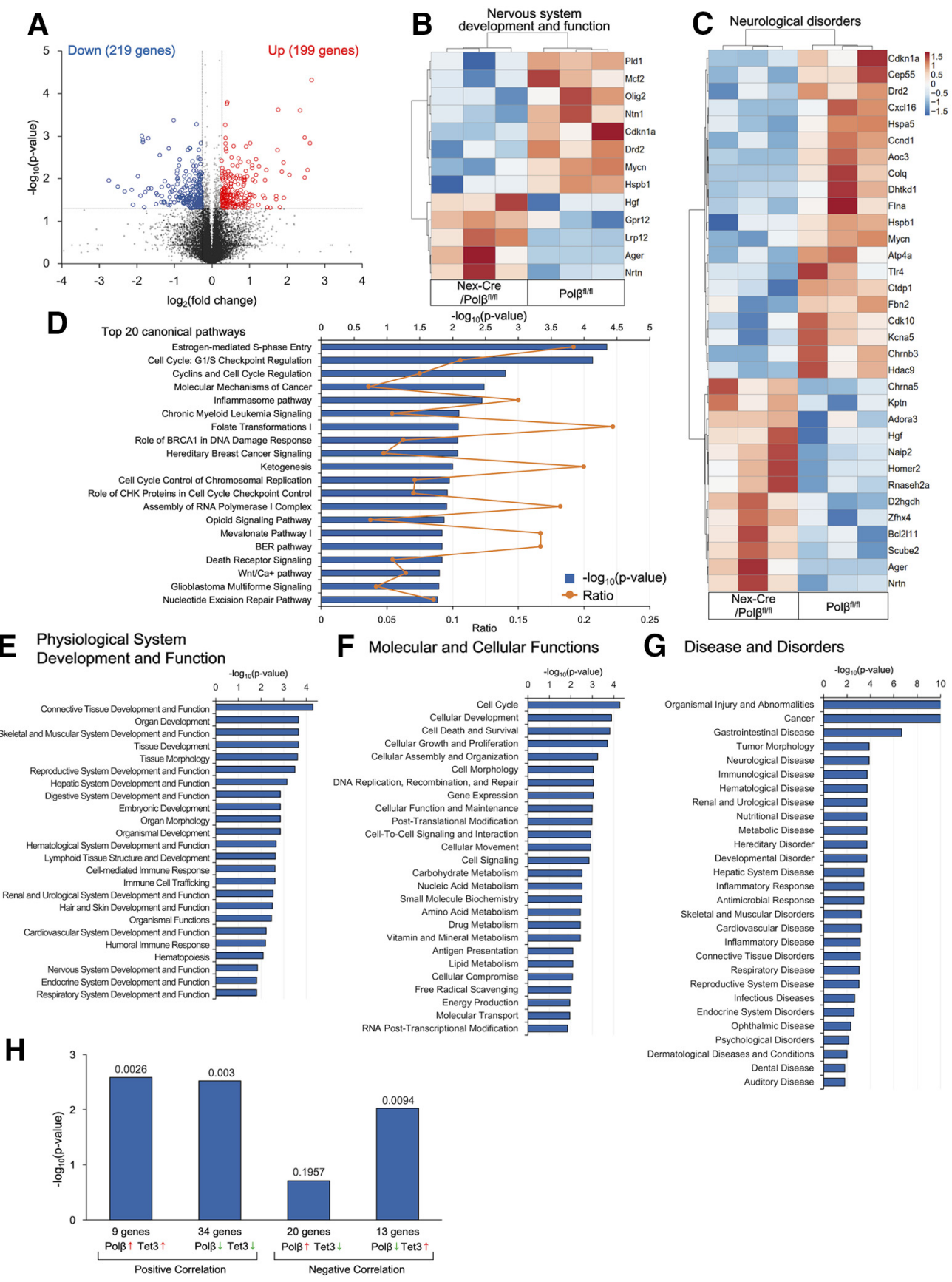

Figure 7. Pol $\beta$ deficiency affects gene expression of hippocampal neurons during postnatal development. $A$, Volcano plot of RNA-seq data from Pol $\beta^{f / f / f}$ and Nex-Cre/Pol $\beta^{f / / f} \mathrm{P} 15$ hippocampus $(n=3)$. DEGs (Nex-Cre/Pol $\beta^{f / f}$ vs Pol $\beta^{f / / f}, p<0.05$, fold change $>1.2$ ) are highlighted in blue (down) or red (up). B, C, Hierarchical clustering with mean-centered log2-FPKM of $D E G s$ related to nervous system development and function $(\boldsymbol{B})$ or neurologic disorders (C). Rows and columns represent genes and samples, respectively. $\boldsymbol{D}$, Top 20 canonical pathways predicted by IPA. $\boldsymbol{E}$-G, Functional annotation of DEGs between Nex-Cre/Pol $\beta^{f / f l}$ and $P o l \beta \beta^{f / f f}$ hippocampus in the three primary categories by IPA $(p<0.05$, Fisher's exact test). $\boldsymbol{H}$, Comparative analysis of DEGs in Pol $\beta$-deficient hippocampus and Tet3 shRNA-transfected hippocampal neuron culture.

\section{Nex-Cre/Pol $\beta^{f l f l}$ mice show impaired spatial reference memory and contextual fear memory}

To further examine the involvement of $\operatorname{Pol} \beta$ in neuronal functions, Nex-Cre/Pol $\beta^{\text {fllfl }}$ mice and their littermates were subjected to a comprehensive behavioral test battery (Shoji et al., 2018). Significant behavioral differences between control and mutant mice were found in several behavioral tests (Extended Data Fig. 9-1). Notably, in the Barnes maze test, which is widely used for assessing spatial learning and memory, the number of errors to reach the target was significantly larger in $\mathrm{Nex}$-Cre/Pol $\beta^{f l / f l}$ mice than in control Pol $\beta^{f l f l}$ mice (Fig. 9A; $p=0.0003$, repeated- measures ANOVA). Consistent with this, the traveling distance and the latency were also significantly different between the two groups (Fig. 9B,C; distance: $p=0.0094$, latency: $p=0.2051$, repeated-measures ANOVA). In the probe test at $1 \mathrm{~d}$ after final trial of the acquisition test, $\mathrm{Nex}-\mathrm{Cre} / \mathrm{Pol} \beta^{\mathrm{fl} / \mathrm{fl}}$ mice spent significantly less time around their targets compared with the control (Fig. $9 D ; 34.6 \pm 3.9 \%, 20.7 \pm 2.1 \%, p=0.0031$, ANOVA), confirming impaired spatial learning and memory because of distal environmental cues. This behavior was observed at 1 month after the acquisition test (Extended Data Fig. 9-1). In the contextual and cued fear conditioning test, which is used to assess fear 


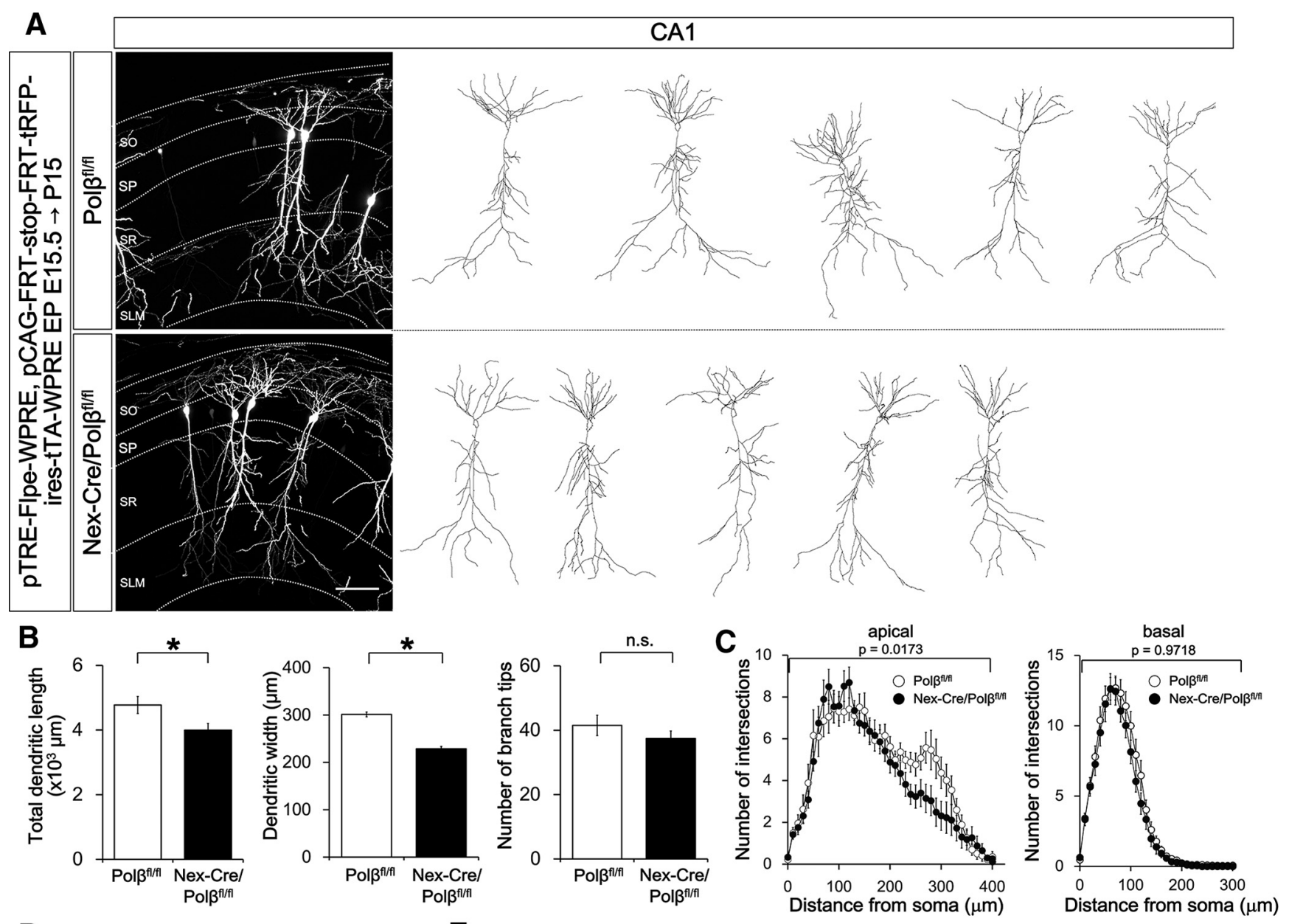

D

\section{E}
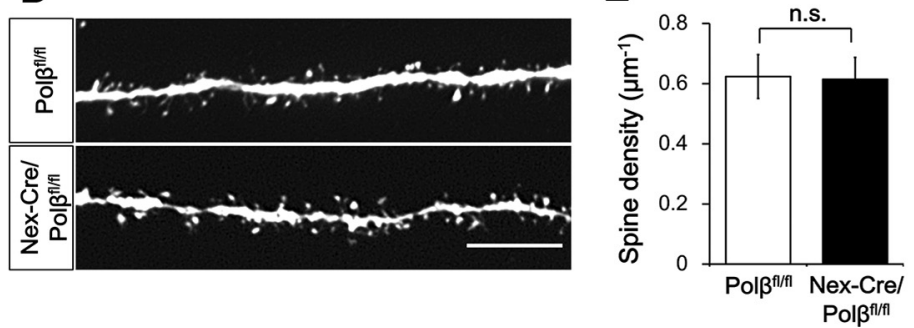

Figure 8. Pol $\beta$ deficiency affects morphology of developing CA1 pyramidal neurons. A, Hippocampal CA1 neurons were cotransfected with FLPe-based Supernova vectors by in utero electroporation at E15.5 and analyzed at P15. Immunohistochemistry was performed with anti-tRFP antibody in Nex-Cre/Pol $\beta^{f / f l}$ and Pol $\beta^{f / f l}$ hippocampus. Examples of z-projected dendritic morphology of CA1 neurons traced with tRFP labeling are shown. Scale bar, $100 \mu \mathrm{m}$. B, Quantitative analysis for total dendritic length, dendritic width, and number of branch tips. Data are mean $\pm \mathrm{SEM}$ from Pol $\beta^{\mathrm{f} / \mathrm{fl}}$ ( $n=18$ cells of 5 animals) and Nex-Cre/Pol $\beta^{\mathrm{f} / \mathrm{fl}}$ ( $n=20$ cells of 4 animals) mice. $* p<0.05$ (ANOVA). C, Sholl analysis of apical and basal dendrites of the same neurons in $\boldsymbol{A}$. The number of intersections with Sholl spheres (10 $\mu \mathrm{m}$ interval) centered at the soma is plotted as the mean \pm SEM. $\boldsymbol{D}$, Examples of spine morphology in apical dendrites of CA1 pyramidal neurons. $\boldsymbol{E}$, Histogram represents mean spine density in $P o l \beta^{f / f / f}\left(n=12\right.$ segments from 3 animals) and Nex-Cre/Pol $\beta^{f / f / f}$ ( $n=6$ segments from 3 animals) mice. The spines were counted in the segment within $100 \mu \mathrm{m}$ of apical dendrites in SLM.

memory, no difference was found in freezing time during the conditioning phase and at $1 \mathrm{~d}$ after the conditioning (Fig. 9E; $p=0.1434$, repeated-measures ANOVA). However, Nex-Cre/Pol $\beta^{\text {flfl }}$ mice showed a shorter freezing time in the contextual test at 1 month after the conditioning, but not in the cued test (Fig. 9F; $p=0.0390$, repeated-measures ANOVA). In addition, Nex-Cre/Pol $\beta^{f l f l}$ mice also showed reduced anxiety behavior in the elevated plus maze (Fig. $9 H, I$; entries into open arms: $p=0.0023$, time in open arms: $p=0.0303$, ANOVA). Taking into consideration that spatial memory, contextual fear memory, and anxiety behavior are dependent on hippocampus function (Kim and Fanselow, 1992; Koopmans et al., 2003; Jimenez et al., 2018), these results suggest that the lack of $\operatorname{Pol} \beta$ tends to impair hippocampus-dependent functions.

\section{Discussion}

The present study demonstrated that the loss of $\operatorname{Pol} \beta$ leads to DSB accumulation in developing hippocampal pyramidal neurons, and to a lesser extent in neocortical neurons, which is attributable to a failure of active DNA demethylation. The DSB accumulation did not induce apoptosis but affected gene expression and dendritic morphology in developing CA1 neurons. Furthermore, behavioral tests demonstrated that the loss of $\operatorname{Pol} \beta$ impaired hippocampaldependent function. These results suggest that genome maintenance by $\operatorname{Pol} \beta$ contributes to hippocampal neuronal differentiation and functional circuit formation via epigenetic regulation of gene expression (Fig. 9J). 
A $O$ Polj frit

Nex-Cre/Pol $\beta^{\text {flff }}$

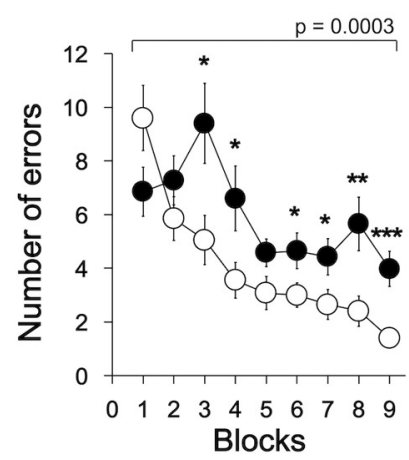

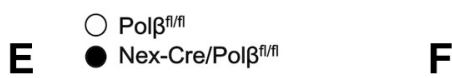

Conditioning
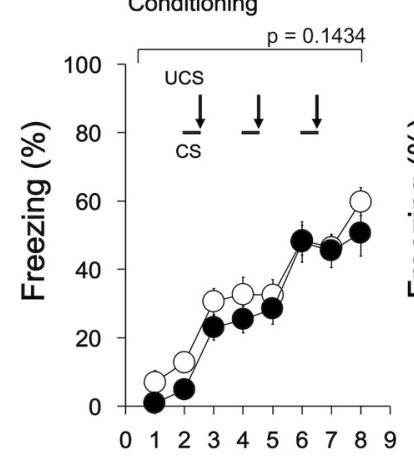

Time (min)
B
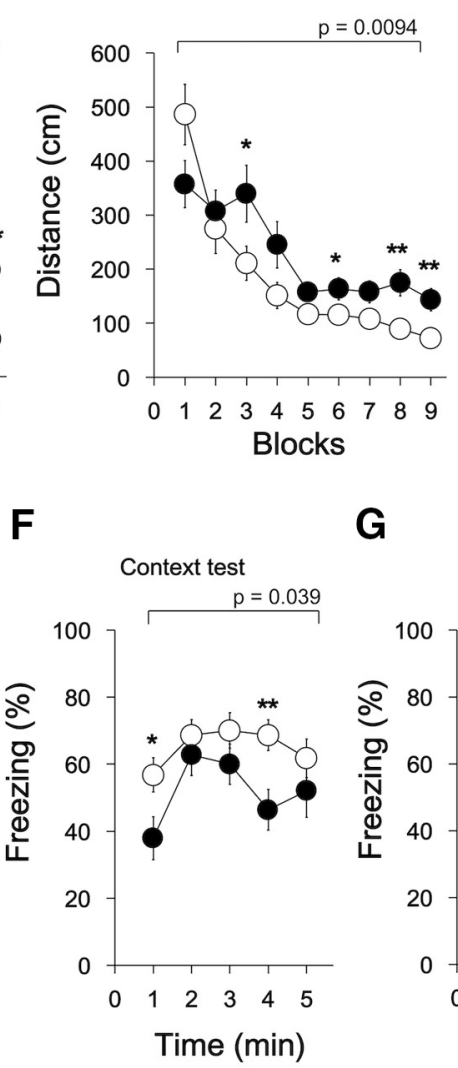

C
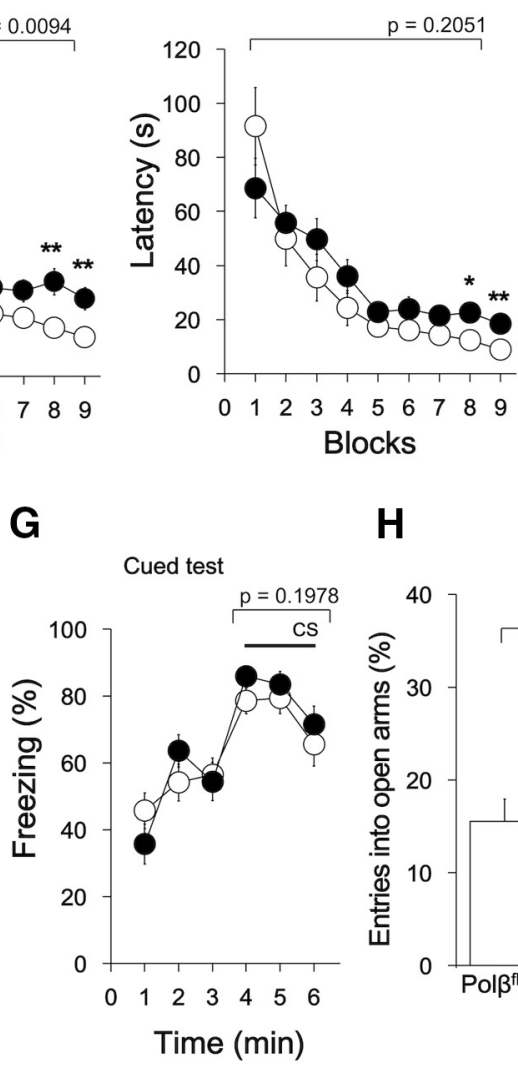

D

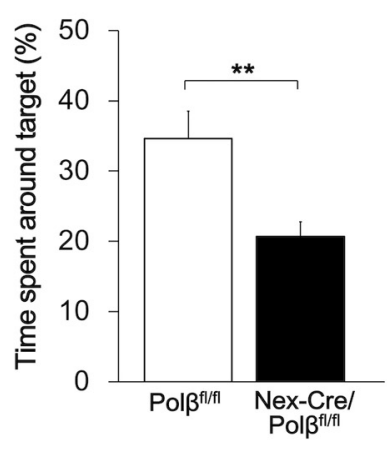

H

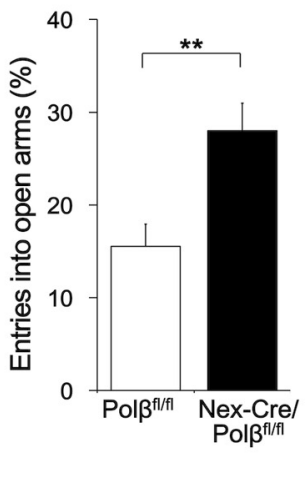

I

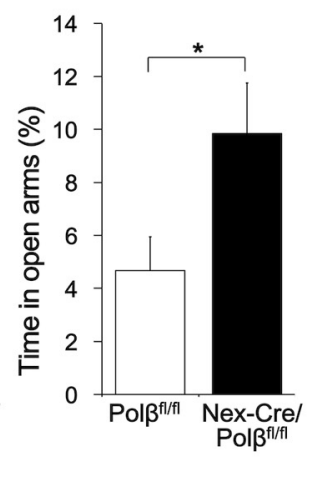

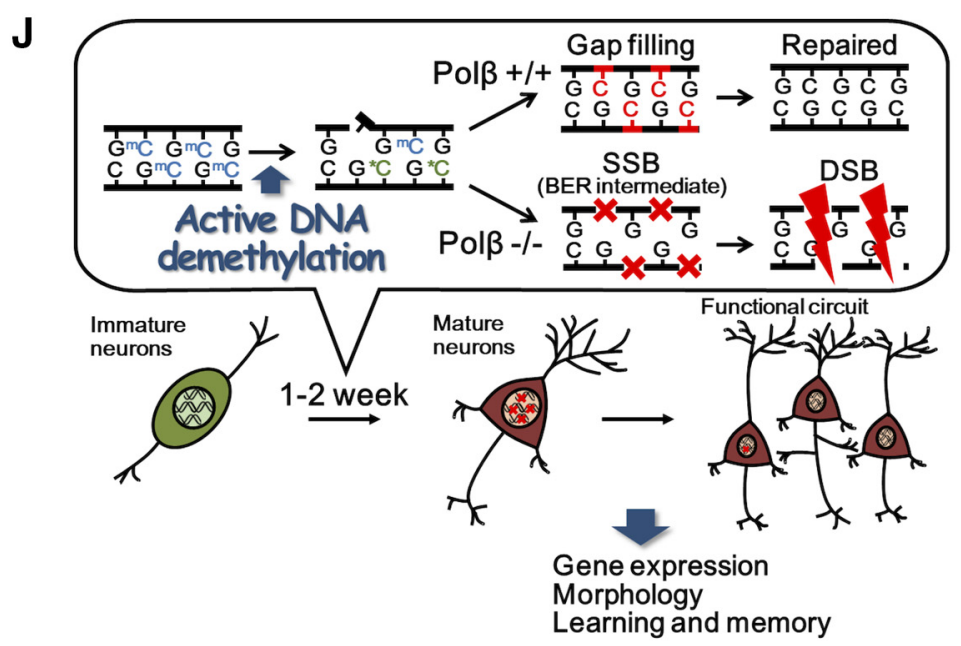

Figure 9. A comprehensive behavioral test with Nex- $\left(\right.$ re/Pol $\beta^{f / f}$ mice show impaired spatial reference memory and contextual fear memory. For all data, see Extended Data Figure 9-1. A$\boldsymbol{D}$, The Barnes maze test was performed for Nex-Cre/Pol $\beta^{f / f / f}(n=20)$ and $P o l \beta \beta^{f / f f}(n=20)$ mice. Quantitative analysis of the number of errors $(\boldsymbol{A})$, distance traveled $(\boldsymbol{B})$, and latency $(\boldsymbol{C})$ before reaching the target hole. Data are mean \pm SEM. $* p<0.05 ; * * p<0.01 ; * * * p<0.001$; repeated-measures ANOVA for 2 blocks of trials. $\boldsymbol{D}$, Histogram represents percentage of time spent around the target in the probe test at $1 \mathrm{~d}$ after the acquisition test. Data are mean \pm SEM. $* * p<0.01$ (ANOVA). $\boldsymbol{E}-\mathbf{G}$, Quantitative analysis of freezing behavior (\%) in the conditioning session $(\boldsymbol{E})$, contextual $(\boldsymbol{F})$, and cued $(\boldsymbol{G})$ test in the fear conditioning test. Data are mean \pm SEM from Nex-Cre/Pol $\beta^{f / / f}(n=20)$ and Pol $\beta^{f / / f}(n=20)$ mice. $* p<0.05 ; * * p<0.01$; repeatedmeasures ANOVA for each duration. $\boldsymbol{H}, \boldsymbol{I}$, Histograms represent quantitative analysis of entries into open arms $(\boldsymbol{H})$ and time spent in open arms $(\boldsymbol{I})$ in the elevated plus maze test. Data are mean \pm SEM from Nex-Cre/Pol $\beta^{f / f f}(n=20)$ and Pol $\beta^{f / f f}(n=20)$ mice. $* p<0.05 ; * * p<0.01$; ANOVA. J, Proposed model of Pol $\beta$-dependent active DNA demethylation during hippocampal neuronal development.

Pol $\beta$-dependent BER is involved in active DNA demethylation during postnatal development of the nervous system

Our results show that $\operatorname{Pol} \beta$ plays a role in an active DNA demethylation process in postmitotic neuronal development (Fig. 6), giving a first insight into its function in epigenome regulation in vivo (Weber et al., 2016; Kim et al., 2020). In the case of DNA demethylation in postmitotic cells, the TET-dependent active process involving BER seems to be a major reaction because the passive process coupled with DNA replication is dysfunctional (Wu and Zhang, 2017). Indeed, the decrease in DNA methylation level was paralleled by accumulation of SSBs, which may be 
BER intermediates, in the developing hippocampal genome (Figs. $4 A, B, 5$ ). The timing between P2 and P15 is roughly consistent with previous studies (Lister et al., 2013; Simmons et al., 2013). Data in the culture experiment (Fig. 6J-M) suggest that vitamin $\mathrm{C}$ is also important to promote active DNA demethylation during this period (Blaschke et al., 2013).

Moreover, $\operatorname{Pol} \beta$ deficiency altered expression of neuronal genes that are involved in transcription regulation (Olig2, Hdac9), the cytoskeleton (Flna, Homer2), and synaptic transmission (Drd2, Chrna5) (Fig. 7A-C). The altered gene expression patterns were observed consistently in all tested samples of hippocampus in $\mathrm{Nex}$-Cre/Pol $\beta^{f l / f l}$ mice, meaning that the alterations are determinate rather than stochastic, as is different from spontaneous DNA base damage (Fig. $7 A-G$ ). Expression profiles of TET3 shRNA knockdown hippocampal neurons are also similar to those of Nex-Cre/Pol $\beta^{f l f l}$ hippocampus (Fig. $7 H$ ) (Rudenko et al., 2013; Yu et al., 2015). These results support the notion that $\operatorname{Pol} \beta$ contributes to specific gene regulation via active DNA demethylation during hippocampal development. The greater abundance of DSBs in $\mathrm{Pol} \beta$-deficient hippocampal pyramidal neurons than in DG granule cells and neocortical neurons may reflect a greater extent of active DNA demethylation, leading to cell-type specific gene expression profiles (Figs. 1, 2, 5). Indeed, recent RNA-seq studies show distinct gene expression profiles in pyramidal and granule cells (Cembrowski et al., 2016; Rosenberg et al., 2018). Therefore, it is likely that $\operatorname{Pol} \beta$-dependent active DNA demethylation is involved in epigenetic regulation of nervous system development, although we need more studies focusing on neuronal cell types, developmental stages, and neural activities (Kaas et al., 2013; Li et al., 2014; Yu et al., 2015; Zhu et al., 2016; Gontier et al., 2018; Kim et al., 2020).

\section{Genome instability arising from $\operatorname{Pol} \beta$ deficiency leads to long-lasting effects on the genome and epigenome, rather than to apoptosis}

We found that $\operatorname{Pol} \beta$ is required for the genome stability of postmitotic neurons (Fig. 2). Combining this observation with previous studies, $\operatorname{Pol} \beta$-dependent BER appears to play a key role in suppressing DSB formation at two distinct developmental stages, namely, neurogenesis and postnatal neuronal differentiation. Why does the loss of $\operatorname{Pol} \beta$ induce DSBs in developing neurons? $\operatorname{Pol} \beta$ deficiency generally increases nicks and/or gaps as SSBs in the genome. Indeed, SSBs increased significantly in $\mathrm{Pol} \beta$-deficient neurons in vivo (Fig. $4 A-C$ ). Although DNA replication can promote DSB formation from a single SSB in the case of mitotic neural progenitors (Onishi et al., 2017), accumulation of SSBs may directly induce DSBs in postmitotic neurons. Supporting this notion, base damage introduced by MMS treatment induced DSBs in $\operatorname{Pol} \beta$-deficient neuronal cultures (Fig. $4 F-H)$. On the other hand, massive cell death was not observed in $\mathrm{Nex}$-Cre/Pol $\beta^{f l / f l}$ hippocampal pyramidal neurons (Fig. 3G$K)$. Induction of apoptosis seems to be dependent on not only the extent of DSBs but also p53 pathway activity (Sugo et al., 2004).

The collapse of the active DNA demethylation process because of loss of $\operatorname{Pol} \beta$ causes DSB formation in postmitotic neurons (Fig. 2). However, the extent of $\gamma \mathrm{H} 2 \mathrm{AX}$ foci in Nex$\mathrm{Cre} / \mathrm{Pol} \beta^{\mathrm{fl} f \mathrm{l} l}$ mice declined after a peak at P15 (Fig. 3). This suggests that DSBs in $\mathrm{Pol} \beta$-deficient neurons are repaired by the DSBR pathway. Considering that postmitotic neurons only have nonhomologous end-joining activity, which is error-prone DNA repair compared with homologous recombination in mitotic cells, mutations such as insertions/deletions are likely introduced into the DSB sites (Lieber, 2010). It will be interesting to determine whether DSBs and/or DSB-induced de novo somatic mutations are intensively introduced into $\mathrm{mC}$-rich enhancer and promoter regions in neuronal genes. Indeed, the human neuronal genome and epigenome are drastically altered in the developing brain, and this probably has a long-lasting influence on the brain into adulthood (Rehen et al., 2005; Cai et al., 2014; Lodato et al., 2015; Wei et al., 2016; Stroud et al., 2017). Recent work has revealed that such alterations are increased in psychiatric diseases, although the underlying mechanism remains uncertain (McConnell et al., 2013; Fromer et al., 2014; Iossifov et al., 2014). Our findings indicate that active DNA demethylation-associated DNA damage is a potential cause of de novo somatic mutations and an aberrant epigenome in brain developmental disorders.

\section{The role of Pol $\beta$ in structure and function of the cerebral cortex}

$\mathrm{Pol} \beta$ plays a role in the molecular bases underlying dendrite formation in hippocampal pyramidal neurons (Fig. 8). To date, TET1 and TET3 have also been shown to be involved in hippocampal synaptic excitability and plasticity (Rudenko et al., 2013; $\mathrm{Yu}$ et al., 2015). These data suggest that DNA demethylation is necessary for hippocampal circuit formation. On the other hand, it has also been demonstrated that the DNA methyltransferases Dnmt1, Dnmt3a, Dnmt3b, and the methyl-CpG binding protein $\mathrm{MeCP} 2$ are involved in dendritic formation in the hippocampus and NCX (Golshani et al., 2005; Moretti et al., 2006; Zhou et al., 2006; Feng et al., 2010; Cohen et al., 2011). Therefore, gene expression mediated by the bidirectional regulation of DNA methylation and demethylation may be crucial for neuronal development and circuit formation.

A comprehensive behavioral test with $\mathrm{Nex}-\mathrm{Cre} / \mathrm{Pol} \beta^{\mathrm{fl} f \mathrm{fl}}$ mice showed a remarkable impairment in spatial reference memory and contextual fear memory (Fig. $9 A-G$ ). This concurs with recent reports suggesting that active DNA demethylation is involved in learning and memory in adult mice (Kaas et al., 2013; Rudenko et al., 2013; Li et al., 2014; Gontier et al., 2018). However, considering that DSB accumulation in $\operatorname{Pol} \beta$-deficient neurons is most prominent in early postnatal stages, we propose that DSBs and/or DSB-induced de novo mutations arising from the impairment of active DNA demethylation alter gene expression leading to circuit formation, and have a long-lasting influence on learning and memory. Indeed, the functional impairment was striking in the hippocampus (Fig. 9; Extended Data Fig. 9-1), in which DSBs accumulated extensively during the early postnatal stages (Figs. 2, 3). Although the extent of DSBs in the NCX is milder than in the hippocampus, we cannot exclude the possibility that the NCX is also involved in this behavioral impairment.

While active DNA demethylation is revealed as a potential source of DNA damage during early postnatal stages in Nex-Cre/ $P o l \beta^{f l f l}$ mice, we cannot completely rule out the possibility that oxidative stress causes DNA damage, leading to cognitive dysfunction in the adult (Wilson and McNeill, 2007). Indeed, $\operatorname{Pol} \beta$ dependent impairment of cognitive function is reportedly accelerated in aged brains and Alzheimer's disease models (Sykora et al., 2015). Moreover, the expression of DNA repair enzymes, including $\operatorname{Pol} \beta$, gradually decreases with increased oxidative DNA damage associated with aging (Nowak et al., 1990; Wilson et al., 2000; Rao et al., 2001; Lu et al., 2004). Therefore, although pathologic changes with aging can affects the role of $\operatorname{Pol} \beta$ in neurons, our findings provide a key insight into its role during early postnatal development, which has long-lasting cognitive and behavioral outcomes. 


\section{References}

Alt FW, Zhang Y, Meng FL, Guo C, Schwer B (2013) Mechanisms of programmed DNA lesions and genomic instability in the immune system. Cell 152:417-429.

Arlotta P, Molyneaux BJ, Chen J, Inoue J, Kominami R, Macklis JD (2005) Neuronal subtype-specific genes that control corticospinal motor neuron development in vivo. Neuron 45:207-221.

Beranek DT (1990) Distribution of methyl and ethyl adducts following alkylation with monofunctional alkylating agents. Mutat Res 231:11-30.

Blaschke K, Ebata KT, Karimi MM, Zepeda-Martínez JA, Goyal P, Mahapatra S, Tam A, Laird DJ, Hirst M, Rao A, Lorincz MC, RamalhoSantos M (2013) Vitamin C induces Tet-dependent DNA demethylation and a blastocyst-like state in ES cells. Nature 500:222-226.

Cai X, Evrony GD, Lehmann HS, Elhosary PC, Mehta BK, Poduri A, Walsh CA (2014) Single-cell, genome-wide sequencing identifies clonal somatic copy-number variation in the human brain. Cell Rep 8:1280-1289.

Capitano F, Gargiuli C, Angerilli A, Maccaroni K, Pelliccia F, Mele A, Camilloni G (2016) RNA polymerase I transcription is modulated by spatial learning in different brain regions. J Neurochem 136:706-716.

Cembrowski MS, Wang L, Sugino K, Shields BC, Spruston N (2016) Hipposeq: a comprehensive RNA-seq database of gene expression in hippocampal principal neurons. Elife 5:e14997.

Cheng J, Guo S, Chen S, Mastriano SJ, Liu C, D’Alessio AC, Hysolli E, Guo Y, Yao H, Megyola CM, Li D, Liu J, Pan W, Roden CA, Zhou XL, Heydari K, Chen J, Park IH, Ding Y, Zhang Y, et al. (2013) An extensive network of TET2-targeting MicroRNAs regulates malignant hematopoiesis. Cell Rep 5:471-481.

Cohen S, Gabel HW, Hemberg M, Hutchinson AN, Sadacca LA, Ebert DH, Harmin DA, Greenberg RS, Verdine VK, Zhou Z, Wetsel WC, West AE, Greenberg ME (2011) Genome-wide activity-dependent MeCP2 phosphorylation regulates nervous system development and function. Neuron 72:72-85.

El-Khamisy SF, Masutani M, Suzuki H, Caldecott KW (2003) A requirement for PARP-1 for the assembly or stability of XRCC1 nuclear foci at sites of oxidative DNA damage. Nucleic Acids Res 31:5526-5533.

Feldblum S, Erlander MG, Tobin AJ (1993) Different distributions of GAD65 and GAD67 mRNAs suggest that the two glutamate decarboxylases play distinctive functional roles. J Neurosci Res 34:689-706.

Feng J, Zhou Y, Campbell SL, Le T, Li E, Sweatt JD, Silva AJ, Fan G (2010) Dnmt1 and Dnmt3a maintain DNA methylation and regulate synaptic function in adult forebrain neurons. Nat Neurosci 13:423-430.

Fromer M, Pocklington AJ, Kavanagh DH, Williams HJ, Dwyer S, Gormley P, Georgieva L, Rees E, Palta P, Ruderfer DM, Carrera N, Humphreys I, Johnson JS, Roussos P, Barker DD, Banks E, Milanova V, Grant SG, Hannon E, Rose SA, et al. (2014) De novo mutations in schizophrenia implicate synaptic networks. Nature 506:179-184.

Goebbels S, Bormuth I, Bode U, Hermanson O, Schwab MH, Nave KA (2006) Genetic targeting of principal neurons in neocortex and hippocampus of NEX-Cre mice. Genesis 44:611-621.

Golshani P, Hutnick L, Schweizer F, Fan G (2005) Conditional Dnmtl deletion in dorsal forebrain disrupts development of somatosensory barrel cortex and thalamocortical long-term potentiation. Thalamus Relat Syst 3:227-233.

Gontier G, Iyer M, Shea JM, Bieri G, Wheatley EG, Ramalho-Santos M, Villeda SA (2018) Tet2 rescues age-related regenerative decline and enhances cognitive function in the adult mouse brain. Cell Rep 22:19741981.

Hevner RF, Shi L, Justice N, Hsueh Y, Sheng M, Smiga S, Bulfone A, Goffinet AM, Campagnoni AT, Rubenstein JL (2001) Tbr1 regulates differentiation of the preplate and layer 6. Neuron 29:353-366.

Hysolli E, Tanaka Y, Su J, Kim KY, Zhong T, Janknecht R, Zhou XL, Geng L, Qiu C, Pan X, Jung YW, Cheng J, Lu J, Zhong M, Weissman SM, Park IH (2016) Regulation of the DNA methylation landscape in human somatic cell reprogramming by the miR-29 family. Stem Cell Rep 7:43-54.

Inestrosa NC, Varela-Nallar L (2015) Wnt signalling in neuronal differentiation and development. Cell Tissue Res 359:215-223.

Iossifov I, O’Roak BJ, Sanders SJ, Ronemus M, Krumm N, Levy D, Stessman HA, Witherspoon KT, Vives L, Patterson KE, Smith JD, Paeper B, Nickerson DA, Dea J, Dong S, Gonzalez LE, Mandell JD, Mane SM, Murtha MT, Sullivan CA, et al. (2014) The contribution of de novo coding mutations to autism spectrum disorder. Nature 515:216-221.
Iwano T, Masuda A, Kiyonari H, Enomoto H, Matsuzaki F (2012) Prox1 postmitotically defines dentate gyrus cells by specifying granule cell identity over CA3 pyramidal cell fate in the hippocampus. Development 139:3051-3062.

Jimenez JC, Su K, Goldberg AR, Luna VM, Biane JS, Ordek G, Zhou P, Ong SK, Wright MA, Zweifel L, Paninski L, Hen R, Kheirbek MA (2018) Anxiety cells in a hippocampal-hypothalamic circuit. Neuron 97:670683.e6.

Kaas GA, Zhong C, Eason DE, Ross DL, Vachhani RV, Ming GL, King JR, Song H, Sweatt JD (2013) TET1 controls CNS 5-methylcytosine hydroxylation, active DNA demethylation, gene transcription, and memory formation. Neuron 79:1086-1093.

Kanda Y (2013) Investigation of the freely available easy-to-use software 'EZR' for medical statistics. Bone Marrow Transplant 48:452-458.

Kim J, Fanselow MS (1992) Modality-specific retrograde amnesia of fear. Science 256:675-677.

Kim J, Kim K, Mo JS, Lee Y (2020) Atm deficiency in the DNA polymerase $\beta$ null cerebellum results in cerebellar ataxia and Itpr1 reduction associated with alteration of cytosine methylation. Nucleic Acids Res 48:36783691.

Koopmans G, Blokland A, van Nieuwenhuijzen P, Prickaerts J (2003) Assessment of spatial learning abilities of mice in a new circular maze. Physiol Behav 79:683-693.

Leid M, Ishmael JE, Avram D, Shepherd D, Fraulob V, Dollé P (2004) CTIP1 and CTIP2 are differentially expressed during mouse embryogenesis. Gene Expr Patterns 4:733-739.

Li X, Wei W, Zhao QY, Widagdo J, Baker-Andresen D, Flavell CR, D'Alessio A, Zhang Y, Bredy TW (2014) Neocortical Tet3-mediated accumulation of 5-hydroxymethylcytosine promotes rapid behavioral adaptation. Proc Natl Acad Sci USA 111:7120-7125.

Lieber MR (2010) The mechanism of double-strand DNA break repair by the nonhomologous DNA end-joining pathway. Annu Rev Biochem 79:181211.

Lindahl T, Wood RD (1999) Quality control by DNA repair. Science 286:1897-1905.

Lister R, Mukamel EA, Nery JR, Urich M, Puddifoot CA, Johnson ND, Lucero J, Huang Y, Dwork AJ, Schultz MD, Yu M, Tonti-Filippini J, Heyn H, Hu S, Wu JC, Rao A, Esteller M, He C, Haghighi FG, Sejnowski TJ, et al. (2013) Global epigenomic reconfiguration during mammalian brain development. Science 341:1237905.

Lodato MA, Woodworth MB, Lee S, Evrony GD, Mehta BK, Karger A, Lee S, Chittenden TW, D'Gama AM, Cai X, Luquette LJ, Lee E, Park PJ, Walsh CA (2015) Somatic mutation in single human neurons tracks developmental and transcriptional history. Science 350:94-98.

Longair MH, Baker DA, Armstrong JD (2011) Simple Neurite Tracer: open source software for reconstruction, visualization and analysis of neuronal processes. Bioinformatics 27:2453-2454.

Lu T, Pan Y, Kao SY, Li C, Kohane I, Chan J, Yankner BA (2004) Gene regulation and DNA damage in the ageing human brain. Nature 429:883891.

Luo W, Mizuno H, Iwata R, Nakazawa S, Yasuda K, Itohara S, Iwasato T (2016) Supernova: a versatile vector system for single-cell labeling and gene function studies in vivo. Sci Rep 6:35747.

Madabhushi R, Pan L, Tsai LH (2014) DNA damage and its links to neurodegeneration. Neuron 83:266-282.

McConnell MJ, Lindberg MR, Brennand KJ, Piper JC, Voet T, CowingZitron C, Shumilina S, Lasken RS, Vermeesch JR, Hall IM, Gage FH (2013) Mosaic copy number variation in human neurons. Science 342:632-637.

McConnell MJ, Moran JV, Abyzov A, Akbarian S, Bae T, Cortes-Ciriano I, Erwin JA, Fasching L, Flasch DA, Freed D, Ganz J, Jaffe AE, Kwan KY, Kwon M, Lodato MA, Mills RE, Paquola AC, Rodin RE, Rosenbluh C, Sestan N, et al. (2017) Intersection of diverse neuronal genomes and neuropsychiatric disease: the Brain Somatic Mosaicism Network. Science 356:eaal1641.

McKinnon PJ (2013) Maintaining genome stability in the nervous system. Nat Neurosci 16:1523-1529.

Moretti P, Levenson JM, Battaglia F, Atkinson R, Teague R, Antalffy B, Armstrong D, Arancio O, Sweatt JD, Zoghbi HY (2006) Learning and memory and synaptic plasticity are impaired in a mouse model of Rett syndrome. J Neurosci 26:319-327. 
Nieto M, Monuki ES, Tang H, Imitola J, Haubst N, Khoury SJ, Cunningham J, Gotz M, Walsh CA (2004) Expression of Cux-1 and Cux-2 in the subventricular zone and upper layers II-IV of the cerebral cortex. J Comp Neurol 479:168-180.

Nowak R, Woszczynski M, Siedlecki JA (1990) Changes in the DNA polymerase beta gene expression during development of lung, brain, and testis suggest an involvement of the enzyme in DNA recombination. Exp Cell Res 191:51-56.

Onishi K, Uyeda A, Shida M, Hirayama T, Yagi T, Yamamoto N, Sugo N (2017) Genome stability by DNA polymerase $\beta$ in neural progenitors contributes to neuronal differentiation in cortical development. J Neurosci 37:8444-8458.

Poduri A, Evrony GD, Cai X, Walsh CA (2013) Somatic mutation, genomic variation, and neurological disease. Science 341:1237758

Rao KS, Annapurna VV, Raji NS (2001) DNA polymerase-beta may be the main player for defective DNA repair in aging rat neurons. Ann NY Acad Sci 928:113-120.

Rehen SK, Yung YC, McCreight MP, Kaushal D, Yang AH, Almeida BS, Kingsbury MA, Cabral KM, McConnell MJ, Anliker B, Fontanoz M, Chun J (2005) Constitutional aneuploidy in the normal human brain. J Neurosci 25:2176-2180

Rogakou EP, Boon C, Redon C, Bonner WM (1999) Megabase chromatin domains involved in DNA double-strand breaks in vivo. J Cell Biol 146:905-916.

Rosenberg AB, Roco CM, Muscat RA, Kuchina A, Sample P, Yao Z, Graybuck LT, Peeler DJ, Mukherjee S, Chen W, Pun SH, Sellers DL, Tasic B, Seelig G (2018) Single-cell profiling of the developing mouse brain and spinal cord with split-pool barcoding. Science 360:176-182.

Ross W, Rowe T, Glisson B, Yalowich J, Liu L (1984) Role of topoisomerase II in mediating epipodophyllotoxin-induced DNA cleavage. Cancer Res 44:5857-5860.

Rudenko A, Dawlaty MM, Seo J, Cheng AW, Meng J, Le T, Faull KF, Jaenisch R, Tsai LH (2013) Tet1 is critical for neuronal activity-regulated gene expression and memory extinction. Neuron 79:1109-1122.

Sanosaka T, Imamura T, Hamazaki N, Chai M, Igarashi K, Ideta-Otsuka M, Miura F, Ito T, Fujii N, Ikeo K, Nakashima K (2017) DNA methylome analysis identifies transcription factor-based epigenomic signatures of multilineage competence in neural stem/progenitor cells. Cell Rep 20:2992-3003.

Schultz LB, Chehab NH, Malikzay A, Halazonetis TD (2000) p53 binding protein 1 (53BP1) is an early participant in the cellular response to DNA double-strand breaks. J Cell Biol 151:1381-1390.

Scorcioni R, Polavaram S, Ascoli GA (2008) L-Measure: a web-accessible tool for the analysis, comparison and search of digital reconstructions of neuronal morphologies. Nat Protoc 3:866-876.

Sharma A, Klein SS, Barboza L, Lohdi N, Toth M (2016) Principles governing DNA methylation during neuronal lineage and subtype specification. J Neurosci 36:1711-1722.

Shoji H, Irino Y, Yoshida M, Miyakawa T (2018) Behavioral effects of longterm oral administration of aluminum ammonium sulfate in male and female C57BL/6J mice. Neuropsychopharmacol Rep 38:18-36.

Simmons RK, Stringfellow SA, Glover ME, Wagle AA, Clinton SM (2013) DNA methylation markers in the postnatal developing rat brain. Brain Res 1533:26-36.
Stroud H, Su SC, Hrvatin S, Greben AW, Renthal W, Boxer LD, Nagy MA, Hochbaum DR, Kinde B, Gabel HW, Greenberg ME (2017) Early-life gene expression in neurons modulates lasting epigenetic states. Cell 171:1151-1164.e16.

Sugo N, Aratani Y, Nagashima Y, Kubota Y, Koyama H (2000) Neonatal lethality with abnormal neurogenesis in mice deficient in DNA polymerase beta. EMBO J 19:1397-1404.

Sugo N, Niimi N, Aratani Y, Takiguchi-Hayashi K, Koyama H (2004) p53 deficiency rescues neuronal apoptosis but not differentiation in DNA polymerase beta-deficient mice. Mol Cell Biol 24:9470-9477.

Sykora P, Misiak M, Wang Y, Ghosh S, Leandro GS, Liu D, Tian J, Baptiste BA, Cong WN, Brenerman BM, Fang E, Becker KG, Hamilton RJ, Chigurupati S, Zhang Y, Egan JM, Croteau DL, Wilson DM, Mattson MP, Bohr VA (2015) DNA polymerase $\beta$ deficiency leads to neurodegeneration and exacerbates Alzheimer disease phenotypes. Nucleic Acids Res 43:943-959.

Tahiliani M, Koh KP, Shen Y, Pastor WA, Bandukwala H, Brudno Y, Agarwal S, Iyer LM, Liu DR, Aravind L, Rao A (2009) Conversion of 5methylcytosine to 5-hydroxymethylcytosine in mammalian DNA by MLL partner TET1. Science 324:930-935.

Tomita K, Kubo K, Ishii K, Nakajima K (2011) Disrupted-in-Schizophrenia1 (Disc1) is necessary for migration of the pyramidal neurons during mouse hippocampal development. Hum Mol Genet 20:2834-2845.

Weber AR, Krawczyk C, Robertson AB, Kuśnierczyk A, Vågbø CB, Schuermann D, Klungland A, Schär P (2016) Biochemical reconstitution of TET1-TDG-BER-dependent active DNA demethylation reveals a highly coordinated mechanism. Nat Commun 7:10806.

Wei PC, Chang AN, Kao J, Du Z, Meyers RM, Alt FW, Schwer B (2016) Long neural genes harbor recurrent DNA break clusters in neural stem/ progenitor cells. Cell 164:644-655.

Williams JT, Christie MJ, Manzoni O (2001) Cellular and synaptic adaptations mediating opioid dependence. Physiol Rev 81:299-343.

Wilson DM, McNeill DR (2007) Base excision repair and the central nervous system. Neuroscience 145:1187-1200.

Wilson SH, Sobol RW, Beard WA, Horton JK, Prasad R, Vande Berg BJ (2000) DNA polymerase beta and mammalian base excision repair. Cold Spring Harb Symp Quant Biol 65:143-155.

Wu X, Zhang Y (2017) TET-mediated active DNA demethylation: mechanism, function and beyond. Nat Rev Genet 18:517-534.

Yu H, Su Y, Shin J, Zhong C, Guo JU, Weng YL, Gao F, Geschwind DH, Coppola G, Ming GL, Song H (2015) Tet3 regulates synaptic transmission and homeostatic plasticity via DNA oxidation and repair. Nat Neurosci 18:836-843.

Zhong Y, Takemoto M, Fukuda T, Hattori Y, Murakami F, Nakajima D, Nakayama M, Yamamoto N (2004) Identification of the genes that are expressed in the upper layers of the neocortex. Cereb Cortex 14:11441152.

Zhou Z, Hong EJ, Cohen S, Zhao WN, Ho HY, Schmidt L, Chen WG, Lin Y, Savner E, Griffith EC, Hu L, Steen JA, Weitz CJ, Greenberg ME (2006) Brain-specific phosphorylation of $\mathrm{MeCP} 2$ regulates activity-dependent Bdnf transcription, dendritic growth, and spine maturation. Neuron $52: 255-269$.

Zhu X, Girardo D, Govek EE, John K, Mellén M, Tamayo P, Mesirov JP, Hatten ME (2016) Role of Tet $1 / 3$ genes and chromatin remodeling genes in cerebellar circuit formation. Neuron 89:100-112. 